\title{
Contrasted distributions of triterpene derivatives in the sediments of Lake Caçó reflect paleoenvironmental changes during the last 20,000 yrs in NE Brazil.
} Jérémy Jacob ${ }^{\mathrm{a}, 1}$, Jean-Robert Disnar ${ }^{\mathrm{a}}$, Mohammed Boussafir ${ }^{\mathrm{a}}$, Ana Luiza Spadano Albuquerque $^{\mathrm{b}}$, Abdelfettah Sifeddine ${ }^{\mathrm{c}}$ and Bruno Turcq ${ }^{\mathrm{c}}$.

${ }^{a}$ Institut des Sciences de la Terre d'Orléans (ISTO), UMR6113 CNRS/Université d'Orléans Bâtiment Géosciences, Rue de Saint Amand, BP 6759, 45067 Orléans Cedex 2.

${ }^{\mathrm{b}}$ IRD/CNPq, Universidade Federal Fluminense, Morro do Valonguinho s/no. 24020-007 Niteroi, Brazil.

${ }^{\mathrm{c}}$ UR055, IRD, Institut de Recherche pour le Développement, 32 av. Henri Varagnat. 93143, Bondy, France.

\begin{abstract}
Lipid fractions extracted from sediment layers deposited in a small Brazilian lake during the last 20,000 yrs were investigated by gas chromatography-mass spectrometry. Considerable differences in the distribution and the amount of triterpene derivatives in the aliphatic as well as in the aromatic fractions were observed all along the series. Although no precise identification of these compounds was undertaken, our interpretation of mass spectral data allowed us discriminating between des-A-triterpenes, mono- and triaromatic derivatives of pentacyclic triterpenes and a series of compounds tentatively identified as diaromatic derivatives of tetracyclic triterpenes. The largest compound diversity was found in the lowest levels of the series dated back to the end of the Last Glacial Maximum when
\end{abstract}

\footnotetext{
${ }^{1}$ Corresponding author.

E-mail address: jeremy.jacob@univ-orleans.fr
} 
good preservation of terrestrial plant debris was ensured by rapid burial in a semi-arid climate. Then, except for a period corresponding to the Younger Dryas, only des-A-lupane was detected in significant amounts. The high predominance of des-A-lupane is interpreted as resulting from the development of a belt of Eleocharis sp. (spike-rush) that filtered most of organic inputs from the catchment and was the site of des-A-lupane production and exportation towards the lake centre. During the Younger Dryas, a strong influx of des-Alupane is attributed to the destruction of the spike-rush belt consecutive to the lowering of the lake level under drier conditions. The temporary destruction of this barrier allowed other triterpene derivatives to reach the lake. The distinct dynamics of des-A and aromatic triterpenes derivatives under variable medium conditions led us to hypothesise that these two families of compounds derive from distinct pools that contributed differently to the sediment depending on environmental and climatic conditions. Des-A-lupane was most probably produced in sub-aquatic conditions within the belt of spike-rush. Reversely, aromatic derivatives of triterpenes could have resulted from the degradation of their biological precursors within reducing micro-environments in the catchment.

\section{Introduction}

Pentacyclic triterpenes constitute a highly diversified family of molecules that are mostly produced by higher plants (Pant and Rastogi, 1979; Das and Mahato, 1983; Mahato et al., 1988; 1992; Mahato and Sen, 1997). Their extensive study for medicinal and pharmaceutical purposes provided abundant information that can be used for taxonomical purposes. Despite the high potentialities they thus offer for reconstructing past depositional environments, neither these compounds nor their diagenetic transformation products are frequently used for such a purpose, especially in recent sedimentary records (Cranwell, 
1984; Hauke, 1994; Jaffé and Hausman, 1995; Prartono and Wolff, 1998). The degradation products of triterpenes also can put some constrains on medium conditions during sediment deposition and early diagenesis. Indeed, the negative consequences that diagenesis can have by reducing structural specificities (Rullkötter et al., 1994, van Aarssen et al., 2000), can be counterbalanced by allowing to trace back the physico-chemical conditions that prevailed when molecular transformations occurred. Numerous studies were carried out on the diagenesis of triterpenes (Spyckerelle, 1975; Corbet, 1980; Lohmann, 1988; ten Haven and Rullkötter, 1988; Trendel et al., 1989; ten Haven et al., 1991; Hauke, 1994; Rullkötter et al., 1994) but the compound transformation routes are still incomplete. Furthermore, few compounds beneficiated from complete identification that forbids the establishment of precise product-precursor relationships. In addition, previous studies were carried out on organic-rich sediments, especially lignites and brown coals that were deposited under oxygen deficient conditions.

This study intends to contribute to our understanding of terrestrial triterpene diagenesis by comparing the distributions of triterpene derivatives in samples deposited under different environmental conditions. The studied samples were collected in the sedimentary infill of a small oligotrophic lake located in Northern Brazil (Figure 1). The major paleoenvironmental changes that have affected the area since the end of the Last Glacial Maximum (LGM) have been assessed from the detailed study of a sedimentary core (Jacob, 2003; Jacob et al., 2004a). The almost exclusive contribution of higher plant material to the sediment and contrasting conditions of degradation offer an outstanding context to monitor the diagenetic fate of higher plant triterpenes and other biomolecules. In previous reports on the biomarker content of these sediments, we discussed on the presence and the significance of onocerane I and of a series of pentacyclic triterpene methyl ethers 
(Jacob et al., 2004b; Jacob et al., 2005). The numerous types of molecular skeletons that have so far been detected in these sediments (namely oleanane, ursane, taraxerane, bauerane, fernane, arborane and onocerane) strengthen the interest of biomarker studies to apprehend the different degradation pathways followed by triterpenes depending on (paleo)environmental conditions.

\section{Materials and methods}

\subsection{Sample selection}

Sixteen samples were selected on a $6 \mathrm{~m}$ core drilled in the sediments of Lake Caçó, in north eastern Brazil (Figure 1). These samples are representative of the five main sedimentary units defined by sedimentology, organic petrography and bulk geochemistry (Jacob et al., 2004a; see paragraph 4.1).

\subsection{Extraction and separation of free lipids}

The method for lipid extraction and separation was described elsewhere (Jacob et al., 2005). Briefly: one gram of dried sediment was ultrasonically extracted with acetonepentane $(50: 50 \mathrm{v} / \mathrm{v})$. The mixture was then separated into a neutral and an acidic fraction by solid phase extraction using AminoPropyl Bond Elute $\subset$ cartridges. Neutral compounds were eluted with $\mathrm{CH}_{2} \mathrm{Cl}_{2}-\mathrm{CH}_{3} \mathrm{OH}(50: 50 \mathrm{v} / \mathrm{v})$ and acidic compounds with ether after acidification of the medium with ether-formic acid $(90: 10 \mathrm{v} / \mathrm{v})$. The neutral fraction was submitted to further fractionation on activated Florisil ${ }^{\circledR}$ to give aliphatic hydrocarbons (eluted with heptane), aromatic hydrocarbons and ethers (with $\mathrm{CH}_{2} \mathrm{Cl}_{2}$ ) and polar 
compounds (with $\mathrm{CH}_{2} \mathrm{Cl}_{2}-\mathrm{CH}_{3} \mathrm{OH} 50: 50 \mathrm{v} / \mathrm{v}$ ). 5 $\alpha$-Cholestane was added as internal standard prior to injection.

\subsection{GC-MS analysis}

GC-MS analyses were performed on a ThermoFinnigan TRACE-PolarisGCQ gas chromatograph-mass spectrometer. The gas chromatograph was fitted with an Rtx ${ }^{\circledR}-5 \mathrm{Sil}$ MS capillary column (30 m x $0.32 \mathrm{~mm}$ i.d., $0.25 \mu \mathrm{m}$ film thickness) with $5 \mathrm{~m}$ of guard column. The GC operating conditions were as follows: temperature hold at $40{ }^{\circ} \mathrm{C}$ for $1 \mathrm{~min}$, then increase from 40 to $120{ }^{\circ} \mathrm{C}$ at $30{ }^{\circ} \mathrm{C} \cdot \mathrm{min}^{-1}, 120$ to $300{ }^{\circ} \mathrm{C}$ at $3{ }^{\circ} \mathrm{C} \cdot \mathrm{min}^{-1}$ with final isothermal hold at $300{ }^{\circ} \mathrm{C}$ over $30 \mathrm{~min}$. The samples were injected splitless, with the injector temperature set at $280{ }^{\circ} \mathrm{C}$. Helium was the carrier gas. The mass spectrometer was operated in the electron ionisation (EI) mode at $70 \mathrm{eV}$ ionization energy and scanned from 50 to 650 Daltons. Compounds were tentatively identified by comparison with published mass spectra and relative retention times. The mass spectra of several compounds discussed in the text are given in the Appendix together with the proposed structures. Because of frequent coelutions, quantitations were performed on ion specific chromatograms drawn with the three major ions of the analysed compounds (see Table 1). Then, the obtained peak areas were normalized to the intensity of the peak of $5 \alpha$-Cholestane, measured on the TIC record. In the ignorance of individual response factors, this procedure forbids the real concentration of individual compounds to be determined but allows us assessing the variations of abundance along the core, which is the scope of this paper. 


\section{Results}

\subsection{Aliphatic hydrocarbons}

Seven compounds eluting between $n \mathrm{C}_{23}$ and $n \mathrm{C}_{25}$ alkanes (Figure 2) in the GC-trace of the aliphatic hydrocarbon fraction of sample 229 (470 cm depth) are interpreted as desA-triterpenes (numbered 1 to 7 after their elution order). Their mass spectral characteristics are summarized in Table 1. Compounds 1 to 4 plus 6 that have a molecular mass of 328 amu $\left(\mathrm{C}_{24} \mathrm{H}_{40}\right)$ were identified as unsaturated des-A-triterpenes. Compounds 5 and 7 that exhibit a molecular ion at $\mathrm{m} / \mathrm{z} 330\left(\mathrm{C}_{24} \mathrm{H}_{42}\right)$ are most certainly saturated counterparts. Compounds 1 to 4, the mass spectra of which do not display any fragment characteristic of the loss of an isopropyl group $[\mathrm{M}-43]^{+}$, are thus identified as des-A-triterpenes having a six-membered ring E. Abundant fragments at m/z 189, 203, 204 and 218 are typical for Cring cleavage in oleanene and ursene structures, followed by retro-Diels Alder rearrangement (Djerassi et al., 1962; Budzikiewicz et al., 1962). According to relative retention times of oleanane and ursane-type triterpenes and mass spectral resemblance with already proposed structures (Logan and Eglinton, 1994; Corbet, 1980), we tentatively identify compound 1 as des-A-olean-13(18)-ene, compound 2 as des-A-olean-12-ene, compound 3 as des-A-urs-13(18)-ene and compound 4 as des-A-urs-12-ene. Compound 5 was identified as 10ß-des-A-lupane by comparison with published mass spectra (Corbet, 1980; Philp, 1985; Trendel et al., 1989; Woolhouse et al., 1992). The mass spectrum of compound 6 displays intense fragments at $m / z 175,161$ and 149 that are common in D:C or E:C-friedo triterpenes (Shiojima et al., 1992). According to Jaffé and Hausmann (1995), compound 6 might be 10ß-des-A-arbor-9(11)-ene. The mass spectrum of compound 7 displays a molecular ion at $330 \mathrm{amu}$, consistent with a des-A-triterpane structure $\left(\mathrm{C}_{24} \mathrm{H}_{42}\right)$. 
It is tentatively identified as des-A-oleanane/ursane by comparison with a published spectrum (Woolhouse et al., 1992).

\subsection{Aromatic hydrocarbons}

In the aromatic fractions, 20 compounds are tentatively identified as aromatic derivatives of triterpenes. They are divided into three main groups with regard to their mass spectra, the most significant fragments of which are listed in Table 1. The mass spectra of compounds from the first group exhibit prominent fragments at $m / z 145,158,172$. The mass spectra of those from the second group show abundant ions at $\mathrm{m} / \mathrm{z}$ 195, 207 and 221. The compounds of the third group are characterized by spectra displaying molecular ions at $\mathrm{m} / \mathrm{z} 340$ or 342 . The chromatographic distributions of these molecules on ion-specific chromatograms are displayed in Figure 3 and their mass spectra are displayed in the Appendix.

\subsubsection{Ring A monoaromatic pentacyclic triterpenes}

The mass spectra of these compounds exhibit molecular ions at $\mathrm{m} / \mathrm{z} 336$ (compound 8), $\mathrm{m} / \mathrm{z} 380$ (compounds 9 and 10), $\mathrm{m} / \mathrm{z} 378$ (compounds 15 and 22), $\mathrm{m} / \mathrm{z} 376$ (compounds 11,12 and 13) and $\mathrm{m} / \mathrm{z} 374$ (compound 26). The mass spectra of compounds 8 to $13,15,22$ and 26 show intense ions at $\mathrm{m} / \mathrm{z} 145,157,158,170$ and 172 that is consistent with A-ring monoaromatic triterpanes with oleanane, ursane or lupane skeletons (Laflamme and Hites, 1978; Wakeham et al., 1980; Chaffee et al., 1984; Hazai et al., 1986; Chaffe and Fookes, 1988; Loureiro and Cardoso, 1990; Stout, 1992). The relative intensities of ions $\mathrm{m} / \mathrm{z}$ 145, $157,158,170$ and 172 depend on whether additional unsaturations are located on rings B, C, D or E. As demonstrated by several authors (Lohmann, 1988; Loureiro and Cardoso, 
1990), the double bond position in natural product precursors is often preserved in diagenetic derivatives. For example, $\Delta^{12}$ oleanenes are transformed into aromatic oleanoids in which the $\Delta^{12}$ double bond is preserved as long as aromatisation does not affect ring C.

The mass spectra of compounds 15 and 22 display an intense ion at $m / z 145$ and minor ions at $\mathrm{m} / \mathrm{z} 157$ and 172 . Their molecular weight of $378 \mathrm{amu}$ is consistent with a $\mathrm{C}_{28} \mathrm{H}_{42}$ formula. Comparable spectra have been described in Hazai et al. (1986), Wolff et al. (1989), ten Haven et al. (1992) and Stout (1992) where they were attributed to ring A monoaromatic triterpenes with oleanane, ursane or lupane structures. Accordingly, we propose the structures of oleana(ursa)-1,3,5(10)-triene and dinor-lupa-1,3,5(10)-triene for compounds 15 and 22, respectively.

The mass spectra of compounds 11,12 and 13 display a molecular ion at $\mathrm{m} / \mathrm{z} 376$ that denotes ring A monoaromatic structures with one double bond $\left(\mathrm{C}_{28} \mathrm{H}_{40}\right)$. Compounds displaying resembling mass spectra have been reported in sub-bituminous coals (Hazai et al., 1986), in Tertiary angiospermous lignite (Stout, 1992) and were identified with synthetic standards (Wolff et al., 1989). According to spectral data and relative retention times, compounds 11,12 and 13 could be dinor-oleana(ursa)-1,3,5(10),13(18)-tetraene isomers.

The molecular ion of compound $26(374 \mathrm{amu})$ is consistent with a $\mathrm{C}_{28} \mathrm{H}_{40}$ formula, i.e. a monoaromatic compound with two additional double bonds. Abundant fragments at $\mathrm{m} / \mathrm{z} 145,157$ and 172 attest to a A-ring monoaromatic structure. No isopropyl loss is expressed by any $[\mathrm{M}-43]^{+}$ion. As suggested by the preservation of the already mentioned ions at $\mathrm{m} / \mathrm{z} 145,157$ and 172, the two additional double bonds cannot be both located on rings $\mathrm{B}$ or $\mathrm{C}$ since this latter configuration would lead to dominant $\mathrm{m} / \mathrm{z} 221$ fragment (Stout, 
1992). Therefore we propose a ring A-aromatic pentacyclic structure derived from oleanane or ursane and bearing two additional double bonds at $\Delta^{12}$ and $\Delta^{18}$ positions for compound 26. The molecular ion at $\mathrm{m} / \mathrm{z} 336$ of compound 8 differs from 42 amu from that of compound 22. This difference could be taken as an evidence that compound 8 is the 22,29,30-trisnor- derivative of compound 22. Therefore, the structure of pentanor-lupa1,3,5(10)-triene is proposed for compound 8.

The mass spectra of both compounds 9 and 10 shows a fragmentation pattern similar to those discussed above (prominent fragments at $m / z 145,157,159,172$ and 173 in the mass spectra) but a molecular weight of $380 \mathrm{amu}\left(\mathrm{C}_{28} \mathrm{H}_{44}\right)$. Such a molecular weight supposes the addition of two hydrogen atoms on the already discussed compounds that exhibit a molecular weight of 378 amu, but without affecting the double bonds that participate to aromatisation. Therefore, compounds 9 and 10 could be ring A-monoaromatic derivatives of seco-triterpenes or of tetracyclic triterpenes possessing a lateral side chain. This latter assumption is corroborated by the presence of an abundant fragment at $\mathrm{m} / \mathrm{z} 351$ in the mass spectra of compound 9 that attests to the loss of an ethyl moiety.

\subsubsection{Triaromatics}

The mass spectra of compounds 20,23 and 24 all exhibit a molecular ion at $\mathrm{m} / \mathrm{z} 342$ and a strong fragment at $\mathrm{m} / \mathrm{z} 257$ that characterise ring $\mathrm{A}, \mathrm{B}, \mathrm{C}$ triaromatic triterpenes (Wakeham et al., 1980; Chaffee and Fookes, 1988; Stout, 1992). Comparison of mass spectral data allowed us to identify compounds 20 and 23 as tetranor-oleana(ursa)$1,3,5(10), 6,8,11,13$-heptaene isomers and compound 24 as tetranor-lupa1,3,5(10),6,8,11,13-heptaene, respectively, with undefined stereochemistry at the $\mathrm{D} / \mathrm{E}$ ring 
junction (Chaffee and Fookes, 1988). The mass spectra of two other compounds (16 and 19) resemble the previous ones, but with a molecular ion at $m / z 340$ and a prominent ion at $\mathrm{m} / \mathrm{z}$ 255. Compounds 16 and 19 are therefore interpreted as ring $\mathrm{A}, \mathrm{B}, \mathrm{C}$ triaromatic triterpenes with an additional double bond, probably with oleanane and ursane structures, respectively.

\subsubsection{Ring A,B diaromatic tetracyclic triterpenes}

The mass spectra of compounds from the third group (compounds 14, 17, 18, 21, 25 and 27) often exhibit prominent fragments at $\mathrm{m} / \mathrm{z} \mathrm{181,195,} 207$ and 221 and a molecular mass of 360, 374 and $376 \mathrm{amu}$. To our knowledge, few reports of such mass spectra have been published (Hazai et al., 1986; Stout, 1992; Killops et al., 1995 and Hauke, 1994). According to this latter author, ions at $\mathrm{m} / \mathrm{z} 195,207$ and 221 with a molecular ion at $\mathrm{m} / \mathrm{z}$ 374 correspond to the A,B-diaromatic 24,25-dinor-arbora-1,3,5,7,9-pentaene. In contrast, in the mass spectrum of 24,25-dinor-arbora-1,3,5(10),9(11)-tetraene (molecular ion at $\mathrm{m} / \mathrm{z}$ 376), major fragments are recorded at $\mathrm{m} / \mathrm{z} 209,219$ and 187 . Therefore, one can hypothesize that the $\mathrm{m} / \mathrm{z} 181,195,207$ and 221 fragments characterise ring A, B diaromatic structures with methyl groups located at the C, D ring junction. This assumption cannot account for compounds 14 and 18. The mass spectra of these compounds both have a base peak at $\mathrm{m} / \mathrm{z} 195$ but a molecular ion at $\mathrm{m} / \mathrm{z} 376\left(\mathrm{C}_{28} \mathrm{H}_{40}\right)$, thus requiring two additional hydrogen atoms as compared with the compound with a molecular ion at $\mathrm{m} / \mathrm{z} 374$. This is incompatible with a structure of diaromatic pentacyclic triterpene. According to these observations, the considered compounds could be ring $\mathrm{A}, \mathrm{B}$ diaromatic derivatives of tetracyclic triterpenes with methyl groups located at $\mathrm{C}(13)$ and $\mathrm{C}(14)$ positions (e.g. lanostane, tirucallane or euphane structures) for which a proposed fragmentation 
mechanism is reported in Figure 4. Because the fragmentation pattern is rather similar for compounds with a molecular ion at $\mathrm{m} / \mathrm{z} 376$ and those with a molecular ion at $\mathrm{m} / \mathrm{z} 374$, the additional double bond in these later cannot occur in the vicinity of rings $\mathrm{C}$ and $\mathrm{D}$ but is most probably located on the lateral side chain. According to these observations, compounds 14 and 18 are tentatively identified as ring A, B diaromatic derivatives of lanostane, euphane or tirucallane type compounds. Differences in the spectral signature of these molecules could arise from different configuration at $\mathrm{C}(13)$ and $\mathrm{C}(14)$ positions. Compounds 21, 25 and 27 appear as possible derivatives of compounds 14 and 18 with one additional double bond. In addition to the isomerism at $\mathrm{C}(13)$ and $\mathrm{C}(14)$ positions, the position of the double bond on the lateral side chain could participate in the diversity of fragmentation patterns. Finally, compound 17, which has a molecular mass of 360, is assumed to have a similar structure with a shorter side chain.

\subsection{Oxygenated triterpenes}

The polar fraction that contains oxygenated triterpenes has been investigated but, as for most of recent lake sediment samples, the large diversity of unknown compounds excludes the possibility to relate the triterpene derivatives to their possible biochemical precursors. Only triterpene methyl ethers were identified (Jacob et al., 2005).

\subsection{Evolution through the core}

In order to interpret the changes in evolution of triterpene derivatives along the studied sedimentary record, we compare it with the evolution of Rock-Eval parameters and $\delta \mathrm{D}$ values of triacontanic $\left(n \mathrm{C}_{30}\right)$ acid that are interpreted in terms of variations of humidity. 


\subsubsection{Rock-Eval}

Rock-Eval results are displayed in Figure 6. A detailed description of Rock-Eval results was published in Jacob et al. (2004a). Total Organic Carbon (TOC) values are lower than $5 \%$ between $6 \mathrm{~m}$ and ca. $3 \mathrm{~m}$ depth before increasing up to ca. $15 \%$ at $2 \mathrm{~m}$, then decreasing and remaining around $10 \%$ in the first meter. HI values range between 200 and $500 \mathrm{mg} \mathrm{HC} \cdot \mathrm{g}^{-1}$ TOC in the lower half of the core and around $150 \mathrm{mg} \mathrm{HC} \cdot \mathrm{g}^{-1}$ TOC in the upper half. Mineral inorganic carbon values (MinC) are very low in the lower half of the core. They are around $1 \%$ upcore except for a single interval where values reaching $3 \%$ attest to the presence of siderite. $\mathrm{TpS} 2$ is the temperature of maximum release of hydrocarbonaceous compounds during pyrolysis, as opposed to the Tmax, the well-known maturity indicator, which is $30-40{ }^{\circ} \mathrm{C}$ lower than $\mathrm{TpS} 2 . \mathrm{TpS} 2$ values are higher than $450{ }^{\circ} \mathrm{C}$ in the lower half of the core except for single intervals characterized by values lower than $400^{\circ} \mathrm{C}$. In the upper half of the core TpS2 values vary between $450{ }^{\circ} \mathrm{C}$ and $430{ }^{\circ} \mathrm{C}$ in the 2.9-2 m interval before remaining stable around $450{ }^{\circ} \mathrm{C}$ upcore.

\subsection{2. $\delta \mathrm{D}$ values of triacontanic acid}

The results concerning hydrogen isotope measurements on individual fatty acids have been published elsewhere (Jacob, 2004). $\delta \mathrm{D}$ values of triacontanic acid average -120 $\%$ in the lower half of the core and decrease abruptly at $2.9 \mathrm{~m}$ down to values averaging $160 \%$. A single event between 2.4 and $1.9 \mathrm{~m}$ is characterized by slightly higher values (i.e. up to $-140 \%$ ). 


\subsubsection{Triterpene derivatives}

The distribution of des-A-lupane does not appear related to that of the other des-Atriterpenes (Figure 5). In order to depict the distinct evolution of these compounds, we report the evolution of the des-A-lupane over des-A-triterpenes ratio in Figure 6.

The abundance of des-A-triterpenes is moderate in the lower half of the core. It increases sharply from $2.4 \mathrm{~m}$, to reach a maximum around $2.2 \mathrm{~m}$. Then it decreases down to $2 \mathrm{~m}$ and before remaining at very low levels. The des-A-lupane over des-A-triterpenes ratio does not show much changes except in the lower quarter of the core where it exhibits much lower values. Aromatic derivatives show intermediate relative abundance from 6 to $4.2 \mathrm{~m}$. Then, and up to $2.3 \mathrm{~m}$, these compounds are negligible in the sediment. Their abundance increases suddenly to reach a maximum value at $2 \mathrm{~m}$ before decreasing towards the top of the core.

\section{Discussion}

\subsection{Organic sedimentation and paleoclimatic changes}

The Pleistocene sand dunes and the laterites that are the only outcropping geological formations in the region exclude any possibility of contamination of Lake Caçó sediments by fossil organic matter (OM). The lacustrine sedimentary infill has been divided into 5 units according to lithofacies, organic petrography and Rock-Eval parameters (Figure 6; Jacob et al., 2004a). The lower unit (U1) consists of fine grained sands of the Pleistocene substratum that will not be discussed further. Unit 2 presents rather low contents of OM (TOC $<5 \%$ ) but consisting in exceptionally well preserved higher plant debris. The high preservation of this material is in particular depicted by low TpS2 values attributable to the presence of fresh biopolymers in the samples (Disnar et al., 2003). This remarkable OM 
preservation is thought to result from the rapid burial of higher plant detritus by episodic but strong mineral inputs in an ephemeral lake (Jacob et al., 2004a). At this time, soils developing on the sand dunes were poorly vegetalized due to a harsh climate with a long dry season as depicted by the high $\delta \mathrm{D}$ values of the triacontanic acid (Fig. 6-e; Jacob, 2004). Sparse vegetation developed in wet hollows. During the short rainy season, sand that was mobilized by heavy showers allowed the burial of OM in these hollows. During unit U3 deposition the climate was slightly more humid than during the previous period. There were still erosive rainfalls but soils were more developed and there was a denser plant cover. The U3-U4 transition marks a drastic change in environmental conditions as depicted by a sudden decrease in HI values, a change in lithology from silts to clays and a sharp decrease in $\delta \mathrm{D}$ values of the triacontanic acid (Fig. 6). These changes are attributed to an increase in the precipitation regime especially with a longer rain season (Jacob, 2004). These rather humid conditions allowed forest development around the lake (Ledru et al., 2001) that became perennial with a notable water level. Nevertheless, the lake waters were well oxygenated as a result of a strong mixing by the westerlies. A belt of Eleocharis sp. (spike-rush) that developed on the lake border hindered any mineral and organic input from the watershed. The sedimentary OM, which was still mainly derived from higher plants, was highly degraded as a result of a rather long stay in oxygenated waters and a very slow burial consequential to low inorganic input (Jacob et al., 2004a). Despite these conditions unfavourable to OM preservation, but thanks to very low allochthonous (watershed) and autochthonous (e.g. diatom frustules) inorganic inputs, samples from U4 and U5 present high TOC values, reaching up to $15 \%$. At ca. $2.2 \mathrm{~m}$ depth, the presence of siderite attests to the development of more reducing conditions during diagenesis. It is followed by a dry 
episode coincident with the Younger Dryas as attested by slightly higher values for the $\delta \mathrm{D}$ values of the triacontanic acid between 2.4 and $1.8 \mathrm{~m}$.

The OM preserved in the sediments is hence essentially derived from terrestrial plants that suffered distinct environmental and diagenetic histories along the record. These highly contrasted conditions during sedimentation and early diagenesis are also depicted by triterpene derivative distributions.

\subsection{Diagenesis of higher-plant triterpenes}

Transformation processes initiating the early diagenesis of higher plants pentacyclic triterpenes are thought to begin during leave senescence (Corbet, 1980; Trendel, 1985; Lohmann, 1988 and references therein), possibly thanks to microbial and/or photochemical mediation (Corbet, 1980). The main degradation routes have already been summarized by various authors (Carruthers and Watkins, 1964; Jarolim et al., 1965; Chaffee and Fookes, 1988; Trendel et al., 1989; Wolff et al., 1989; Stout, 1992; Rullkötter et al., 1994). Basically, the first step in higher plant pentacyclic triterpene degradation is the loss of the oxygenated function at $\mathrm{C}(3)$ position from unsaturated compounds such as $\alpha$ and $\beta$ amyrins. This leads to the corresponding di-unsaturated counterparts such as ursadiene and oleanadiene (ten Haven et al., 1992). After this primary transformation, various pathways lead to (i) the formation of $\Delta^{2}$ triterpenes, $\Delta^{2, \mathrm{x}}$ triterpadienes or ring A contracted triterpenes (Elgamal et al., 1969; Ekweozor et al., 1979; ten Haven et al., 1992); (ii) the progressive aromatisation of the skeleton from ring A to finally produce fully aromatised pentacyclic moieties (Laflamme and Hites, 1978; Wakeham et al., 1980; Wolff et al., 1989); (iii) the loss of ring A (des-A-compounds), followed by the progressive aromatisation towards ring 
E (Corbet, 1980; Trendel et al., 1989). The loss of ring A is initiated by its opening leading to the formation of A-seco- intermediates, a phenomenon that readily occurs in plant leaves under photochemical/photomimetic control (Corbet, 1980).

\subsection{Triterpene fingerprint}

The various triterpene derivatives detected in the sediments of Lake Caçó are listed in Table 1 together with their main mass spectral data. Their variety highlights the large contribution of higher plant $\mathrm{OM}$ to the sediments. This is fully consistent the wide diversity of triterpenes already reported in previous studies (onocerane: Jacob et al., 2004b; "PTME": Jacob et al., 2005). If one excludes onocerane and some hopanoids, the only triterpenes found in the non-aromatic fractions of Lake Caçó sediments are des-A derivatives. Nor saturated tetra- or pentacyclic triterpane, neither $\Delta^{2}$ triterpenes or $\Delta^{2, \mathrm{x}}$ triterpadienes were found in the sample extracts. In contrast to unsaturated and fully saturated compounds which require several reaction steps to be formed from a parent triterpenoid, the corresponding triterpadiene only requires the loss of the alcohol functionnal group. Thus, the absence of such compounds is explained by the fact that these olefinic compounds only acted as transitory intermediates in the degradation of original triterpenes into aromatics and/or des-A-triterpenes, depending on medium conditions. For triterpenes, another reaction pathway would be the direct elimination of the oxygenated function of natural triterpenes together with their double bond. Such reactions would require much more reducing conditions than those which developed in Lake Caçó sediments. Finally, the absence of triterpanes and of their mono- and di-unsaturated counterparts is consistent with the conclusions from Spyckerelle (1975) who propose that, 
in contrast to hopanoids, the early diagenetic transformation of higher plant triterpenes preferentially leads to aromatics or des-A-triterpenes rather than to unsaturated or saturated pentacyclic compounds.

Surprisingly, the fingerprints of aromatic derivatives in samples taken at 1.6 and 4.7 m depth globally resemble those described by Stout (1992) and Hazai et al. (1986) for a lignite and a sub-bituminous coal, respectively. They comprise a series of monoaromatic pentacyclic compounds with various structures and degrees of unsaturation, a series of pentacyclic triaromatics and a series interpreted as diaromatic derivatives of tetracyclic triterpenes. Concerning these latter ones, Stout (1992) and Hazai et al. (1986) also detected compounds the mass spectra of which displayed a $\mathrm{m} / \mathrm{z} 195$ ion as dominant peak. We here propose a first tentative identification of this series of compounds as diaromatic tetracyclic triterpenes of the lanostane/euphane series. This tentative identification is substantiated by the presence, in the considered samples, firstly of a methyl ether having such a structure (Jacob et al., 2005), and secondly, by the presence of a ketone and an alcohol derivative in more polar fractions (unpublished results). No ring A,B diaromatic triterpene derivative, fully aromatised triterpene or aromatic derivative of des-A-triterpene was detected in the studied aromatic fractions. The absence of ring A,B diaromatic derivatives could be explained by the pre-existence of one or two double bonds on the rings $\mathrm{C}$ or $\mathrm{D}$ of molecular precursors ( $\beta$ - and $\alpha$-amyrin). As suggested by Lohmann (1988), little additional energy is necessary to aromatise ring $\mathrm{C}$ following rings $\mathrm{A}$ and $\mathrm{B}$ when one or two double bonds already exist on ring $\mathrm{C}$. This explains the sole occurrence of mono- and triaromatic derivatives of pentacyclic triterpenes. Such an absence of A-B diaromatic derivatives of pentacyclic triterpenes was also noted by Stout (1992) who did not either detect any 
aromatic derivative of des-A-triterpene in the Brandon lignite. The co-occurrence of des-Atriterpenes and mono- and triaromatic derivatives of triterpenes in our samples, without any des-A-triterpene aromatic derivative, indicates that the aromatisation of des-A-triterpenes was hindered or that adventitious aromatic des-A-triterpenes were rapidly degraded once formed. The aromatisation of triterpene biomolecules is unlikely to occur in oxygenated waters (Jaffé et al., 1995). Therefore, this phenomenon most probably occurred before functionalized triterpenes entered the water column and the sediment. Finally, no fully aromatised triterpene was found in the selected samples. This highlights that more drastic diagenetic conditions or longer times (Jaffé and Hausmann, 1995) are required to further aromatise the precursor compounds. In summary, the coexistence of des-A-triterpenes and triterpenes derivatives with various degrees of unsaturation/aromatization substantiates the possibility that there were distinct pools of triterpene precursors and/or that it existed different diagenetic pathways in the studied system (i.e. lake surroundings plus water column and sediment) throughout the lake history.

\subsection{Evolution of triterpene derivatives fingerprint along the sedimentary record}

As shown in Figure 6, the distribution of triterpene derivatives (des-A-triterpenes on one hand and aromatic derivatives on the other hand) in the sedimentary record allows us to distinguish three sections differing in the abundance and/or the nature of such compounds. Section 1 coincides with unit U2. Section 2 corresponds to U3, the base of U4 and the uppermost recent part of the series that belong to U5. Section 3 extends from ca. $2.4 \mathrm{~m}$ up to $0.6 \mathrm{~m}$ depth. 


\subsubsection{Section 1}

The samples from this section reveal a great diversity of triterpene derivatives: monounsaturated and saturated des-A-triterpenes (des-A-lupane and compound 7), mono and triaromatic derivatives of pentacyclic triterpenes and diaromatic derivatives of tetracyclic triterpenes. Such compound distributions are very comparable to those described in previous studies, especially on brown coals and lignite (Stout, 1992; Hazai et al., 1986) and are also consistent with the conditions of $\mathrm{OM}$ deposition and diagenesis of the considered section, at the end of the Last Glacial Maximum (ca. 18,000 yrs cal BP). Fresh higher plant debris were rapidly buried by sands mobilized from the denuded substratum during rare but abundant tropical rainfalls (Jacob et al., 2004a). These distributions are also fully consistent with the well-admitted ideas on triterpenes diagenesis: (i) a very early transformation of original triterpenes that can steadily occurs in senescent leaves and thus does not require extensive diagenesis; (ii) two main diagenetic pathways that prevail under dysoxic conditions and lead either to des-A-triterpenes or to mono- and triaromatic derivatives of triterpenes.

The alternation of a long dry season and a short raining season during which the ephemeral lake developed (Jacob, 2004) could straightforwardly substantiate two distinct degradation modes of triterpene biomolecules: (i) firstly, the formation of aromatic derivatives during the dry season, in aerial conditions; (ii) secondly, the production of desA-triterpenes from their triterpene precursors in sub-aquatic conditions during the rainy season. This latter conclusion is in agreement with the assumptions of Trendel (1985) who remarked that the formation of des-A-triterpenes is favoured in soils or sediments that are at least temporarily submerged. 


\subsubsection{Section 2}

In contrast to Section 1, des-A-lupane is by far the dominant triterpene derivative in Section 2 (Figure 5). There, des-A-lupane can represent up to $80 \%$ of the total amounts of des-A-triterpenes (Figure 6-g). Other des-A-triterpenes with oleanane, ursane or arborane structures were only found in low amounts around $2 \mathrm{~m}$ depth (see paragraph 5.4.1.). In addition, there are very few or even no aromatic derivatives in this Section 2 (Figure 6-h). Such a low molecular diversity and the high predominance of des-A-lupane can be interpreted as resulting from (i) a higher sensibility of other des-A-triterpenes than des-Alupane and aromatic derivatives to degradation into the lake water column and sediment; (ii) environmental changes leading to changing sources (vegetation) and transportation modalities. The almost uniqueness of des-A-lupane in the specified samples can result from its preferential formation or peculiar resistance to diagenetic transformations. In contrast to the most common higher plant pentacyclic triterpenes ( $\alpha$ - and $\beta$-amyrins for example), biomolecules with a lupane structure often own an external double bond on the isopropyl group. Under favourable conditions the external location of this double bond would favour its reduction rather than the initiation of aromatisation that is facilitated in the presence of an internal double bond (in $\Delta^{12}$ position for example in $\alpha$ - and $\beta$-amyrins). In addition, desA-lupane is relatively stable to diagenesis. Therefore, the exclusiveness of des-A-lupane in Section 2 could indicate harsh diagenesis whereas its co-occurrence with other des-Atriterpenes in Section 1 and at ca. $2 \mathrm{~m}$ depth (Figure 5) would result from better preservation conditions. However, this hypothesis is somewhat weakened by a closer study of Section 2. The sharp decrease in HI values recorded at ca. $2.9 \mathrm{~m}$ (i.e. U3/U4 transition) attests to a marked change in OM preservation conditions that is not recorded by triterpene 
fingerprints. Therefore, diagenetic conditions cannot solely be invoked for the distributions of triterpene derivatives in the considered section. Alternatively, the upcore strong predominance of des-A-lupane could be related to specific environmental conditions. Presently, the belt of Eleocharis $s p$. (from 1 to $3 \mathrm{~m}$ depth; Figure $7 \mathrm{a}$ ) practically prevents any organic input from the watershed. In addition, the relatively high productivity in the protected medium that constitutes this belt, leads there to more reducing conditions than in the open basin (under oligotrophic conditions). We did not determine the triterpenes of Eleocharis sp. However, previous investigations showed that the pentacyclic triterpenes synthesized by this species are of the lupane type, namely betulinic acid, betulin and lup20(29)-en-3 $\beta, 16 \beta$-diol, with minor contributions from neohop-13(18)-en-3 $\alpha$-ol and fern9(11)-en-3 $\alpha$-ol (Miles et al., 1994; Amaral et al., 2004). Similarly, geochemical investigations of surficial sediments from a marsh covered with Eleocharis sp. and developing within a mangrove system did not show any pentacyclic triterpene but lupeol (Koch et al., 2003). Accordingly, it can be hypothesized that des-A-lupane could originate from lupane-type precursors synthesized by Eleocharis sp., whereas other triterpenes are subordinates. The sub-aerial and reducing conditions that prevailed within the Eleocharis $s p$. belt could favour the transformation of lupane-type precursors into des-A-lupane, again in agreement with the observations of Trendel (1985). Then, des-A-lupane would be exported to the open basin to be buried with no or only limited degradation. As previously assumed in paragraph 4.4.2., aromatisation processes do not occur in the water column or even in the sediment. Therefore, aromatic derivatives must have been produced in the watershed, before reaching the lake. For sediments belonging to Section 2, such compounds were most probably filtered by the Eleocharis $s p$. belt as were non lupane-type des-A- 
triterpenes. Altogether, the predominance of des-A-lupane over other triterpene derivatives in Section 2 could attest to the settling of the Eleocharis $s p$. belt around the lake, first during the deposition of the sediments that are presently found at ca. $4.5 \mathrm{~m}$ depth, and, secondly, in recent times.

\subsubsection{Section 3}

The short episode depicted by high amounts of des-A-lupane between 2.3 and $3 \mathrm{~m}$ (Figure 6-f) is interpreted as resulting from the destruction of the Eleocharis sp. belt, entailing a strong influx of Eleocharis sp.-derived material (and especially des-A-lupane) to the sediment. Subsequently, the disappearance of this barrier also allowed the strong discharge of aromatic derivatives to the sediment (Figure 6-g). The destruction of the Eleocharis sp. belt was probably favoured by a lowering of the lake level as a consequence of dry conditions illustrated by rather high $\delta \mathrm{D}$ values of the triacontanic acid, during this episode.

\subsection{Paleoenvironmental scenario}

The scenario leading to the distinct triterpene derivative fingerprints detected in the sedimentary record is summarized in Figure 7. In Section 1, the degradation of triterpene biomolecules occurred under reducing conditions due to rapid burial. During the short wet season, the development of an ephemeral lake with a low water level, allowed the (sub-) aquatic degradation of triterpene biomolecules into des-A derivatives. More seasonal precipitations during the deposition of Section 2 sediments were responsible for the development of lacustrine conditions and of a belt of Eleocharis sp. This belt was the site 
of production of the precursor(s) of the des-A-lupane that was exported to the sediment. The Eleocharis sp. belt also hindered the input of organic products from the catchment. During the deposition of Section 3, more arid conditions (due to longer dry seasons) provoked a lowering of the lake level. Then, the destabilization of the Eleocharis sp. belt entailed the exportation towards the centre of the lake of the OM that had accumulated within the belt, with a notable contribution of des-A-lupane (Step 1). The OM that had accumulated in more or less reducing micro-environments within the watershed, and/or that could not have reached the lake because of the presence of the Eleocharis sp. belt, was also partly leached and transported to the sediment (Step 2). When the Eleocharis sp. belt builded up again under more stable climatic conditions (Section 2 in upper most levels of the core), detrital material from the watershed with associated aromatic derivatives could not anymore reach the basin. Then, only the OM produced within the Eleocharis sp. and the associated des-A-lupane could contribute to the sediment.

\section{Conclusions}

The detection of various by-products of biological triterpenes (des-A-triterpenes and aromatic derivatives of triterpenes) and their screening in the hydrocarbon extracts of sediments pertaining to a $6 \mathrm{~m}$ long core, allowed us to get an insight into the origin and the dynamics of these compounds depending on environmental conditions. Presumably, des-Atriterpenes and aromatic derivatives of triterpenes were both produced in anoxic or at least dysaerobic environments. Nevertheless, the respective dynamics of these two groups of compounds depends on distinct early diagenetic transformation pathways that probably occurred within distinct (micro-) environments. Although this hypothesis would require further investigations, the relative abundance of des-A-triterpenes and aromatic derivatives 
of pentacyclic triterpenes could provide an index of the degree of hydromorphism of the ecosystems where the sedimentary OM was produced, within the watershed of lacustrine systems. We also tentatively identified a new class of compounds that would result from the aromatisation of higher plant tetracyclic triterpenes with euphane/lanostane basic structures.

\section{Acknowledgements}

This research has been supported by an IRD (France)-CNPq (Brasil) convention and an ISTO (UMR 6113 du CNRS, France)-IRD cooperation. One of us (J. J.) received financial support from the Conseil Régional du Centre. The authors wish to thank Pr. J.K. de Leeuw, Pr. J. Rullkötter, Dr. P. Schaeffer and two anonymous reviewers for their constructive remarks on a previous version of the manuscript.

\section{References}

van Aarssen, B.G.K., Alexander, R., Kagi, R. I., 2000. Higher plant biomarkers reflect palaeovegetation changes during Jurassic times. Geochimica et Cosmochimica Acta 64, $1417-1424$.

Amaral, M.C.E., Faria, A.D., Magalhães, A.F., Magalhães, E.G., Ruiz, A.L.T.G., 2004. Steroids and triterpenes from Eleocharis acutangula and E. sellowiana (Cyperaceae). Phytochemical Analysis 15, 125-129.

Budzikiewicz, H., Wilson, J.M., Djerassi, C., 1962. Mass spectrometry in structural and stereochemical problems. XXXII. Pentacyclic triterpenes. Journal of the American Chemical Society 85, 3688-3699.

Carruthers, W., Watkins, D.A.M., 1964. The constituents of high-boiling petroleum 
distillates. VIII. Identification of 1,2,3,4-tetrahydro-2,2,9-trimethylpicene in an American crude oil. Journal of the Chemical Society of London, 1964, 724-729.

Chaffee, A. L., Fookes, C.J.R., 1988. Polycyclic aromatic hydrocarbons in Australian coals-III. Structural elucidation by proton nuclear magnetic resonance spectroscopy. Organic Geochemistry 12, 261-271.

Chaffee, A. L., Strachan, M. G., Johns, R. B., 1984. Polycyclic aromatic hydrocarbons in Australian coals: novel tetracyclic components from Victorian brown coal. Geochimica et Cosmochimica Acta 48, 2037-2043.

Corbet, B., 1980. Origine et transformation des triterpènes dans les sédiments récents. $\mathrm{PhD}$ thesis, Université Louis Pasteur, Strasbourg, France, 106 p.

Cranwell, P.A., 1984. Organic geochemistry of lacustrine sediments: triterpenoids of higher plant origin reflecting post-glacial vegetational succession. In: Haworth, E.Y. and Lund, J.W.G. (Eds), Lake sediments and environmental history. University Press, Leicester. pp. 69-92.

Das M.C., Mahato S.B., 1983. Triterpenoids. Phytochemistry 22, 1071-1095.

Disnar, J. R., Guillet, B., Kéravis, D., Di-Giovanni, C., Sebag, D., 2003. Soil organic matter (SOM) characterisation by Rock-Eval pyrolysis: scope and limitations. Organic Geochemistry 34, 327-343.

Djerassi, C., Budzikiewicz, H., Wilson, J.M., 1962. Mass spectrometry in structural and stereochemical problems. Unsaturated pentacyclic triterpenoids. Tetrahedron Letters, 263270.

Ekweozor, C.M., Okogun, J.I., Ekong, D.E.U., Maxwell, J.R, 1979. Preliminary organic geochemical studies of samples from the Niger Delta (Nigeria). II. Analyses of shale for triterpenoid derivatives. Chemical Geology 27, 29-37. 
Elgamal, M.H.A., Fayez, M. B. E., Kemp, T. R, 1969. The mass spectra of some triterpenoid dehydration products. Organic Mass Spectrometry 2, 175-194.

Hauke V., 1994. Reconstruction de paléoenvironnements de dépôts en séries sédimentaires: étude au moyen de marqueurs biologiques. PhD thesis, Université Louis Pasteur, Strasbourg, France, 252 p.

ten Haven, H.L., Rullkötter, J., 1988. The diagenetic fate of taraxer-14-ene and oleanene isomers. Geochimica et Cosmochimica Acta 52, 2543-2548.

ten Haven, H. L., Peakman, T.M., Rullkötter, J., 1991. $\Delta^{2}$-triterpenes: early intermediates in the diagenesis of terrigenous triterpenoids. Geochimica et Cosmochimica Acta 56, 19932000.

ten Haven, H. L., Rullkötter, J., Stein, R, 1992. Preliminary analysis of extractable lipids in sediments from the eastern North Atlantic (Leg 108): Comparison of a coastal upwelling area (Site 658) with a non upwelling area (Site 659). Proceedings of the Ocean Drilling Project Scientific Results 108, 351-360.

Hazai, I., Alexander, G., Szekely, T., Essinger, B., Radek, D., 1986. Investigations of hydrocarbons constituents of a young sub-bituminous coal by gas chromatography-mass spectrometry. Journal of Chromatography 367, 117-133.

Jacob, J., 2003. Enregistrement des variations paléoenvironnementales depuis 20000 ans dans le Nord Est du Brésil (Lac Caçó) par les triterpènes et autres marqueurs organiques. PhD thesis, Université d'Orléans, France, 296 p.

Jacob, J., 2004. Water balance over the last 20,000 yrs in North-Eastern Brazil. Insights from the $\delta \mathrm{D}$ variations of fatty acids from a lacustrine series (Lagoa do Caçó). EAOG Newsletter 18, 6-10. 
Jacob, J., Disnar, J.R., Boussafir, M., Sifeddine, A., Albuquerque, A.L.S., Turcq, B., 2004a. Major environmental changes recorded by lacustrine sedimentary organic matter since the Last Glacial Maximum under the tropics (Lake Caçó, NE Brazil). Palaeogeography, Palaeoclimatology, Palaeoecology 205, 183-197.

Jacob, J., Disnar, J.R., Boussafir, M., Ledru, M.-P., Sifeddine, A., Albuquerque, A.L.S, Turcq, B., 2004b. Onocerane attests to dry climatic events during the Quaternary in the Tropics. Organic Geochemistry 35, 289-297.

Jacob, J., Disnar, J.R., Boussafir, M., Sifeddine, A., Albuquerque, A.L.S., Turcq, B., 2005. Pentacyclic triterpene methyl ethers in recent lacustrine sediments (Lake Caçó, Brazil). Organic Geochemistry 36, 449-461.

Jaffé, R., Hausmann, K.B., 1995. Origin and early diagenesis of arborinone/isoarborinol in sediments of a highly productive freshwater lake. Organic Geochemistry 22, 231-235.

Jaffé, R., Wolff, G.A., Cabrera, A.C., Carvajal-Chitty, H.I., 1995. The biogeochemistry of lipids in rivers of the Orinoco Basin. Geochimica et Cosmochimica Acta 59, 4507-4522.

Jarolim, V., Hejno, K., Hemmert, F., Sorm, F., 1965. Über die Zusammensetzung der Braunkohle, IX. Über einige aromatische Kohlenwasserstoffe des Harzanteils des Montanwachses. Collection of Czechoslovak Chemical Communications 30, 873-879.

Killops, S.D., Raine, J.I., Woolhouse, A.D., Weston R.J., 1995. Chemostratigraphic evidence of higher-plant evolution in the Taranaki Basin, New-Zealand. Organic Geochemistry 23, 429-445.

Koch, B.P., Rullkötter, J., Lara, R.J., 2003. Evaluation of triterpenols and sterols as organic matter biomarkers in a mangrove ecosystem in northern Brazil. Wetlands Ecology and Management 11, 257-263. 
LaFlamme, R.E., Hites, R.A., 1978. The global distribution of polycyclic aromatic hydrocarbons in recent sediments. Geochimica et Cosmochimica Acta 42, 289-303.

Ledru, M.P., Cordeiro, R.C., Dominguez, J.M.L, Martin, L., Mourguiart, P., Sifeddine, A. and Turcq, B., 2001. Late-glacial cooling in Amazonia as inferred from pollen at Lagoa do Caçó, Northern Brazil. Quaternary Research 55, 47-56.

Logan, G.A., Eglinton, G., 1994. Biogeochemistry of the Miocene lacustrine deposit, at Clarkia, northern Idaho, U.S.A. Organic Geochemistry 21, 857-870.

Lohmann, F., 1988. Aromatisations microbiennes de triterpènes végétaux. $\mathrm{PhD}$ thesis, Université Louis Pasteur, Strasbourg, France.

Loureiro, M.R.B., Cardoso, J.N., 1990. Aromatic hydrocarbons in the Paraiba Valley oil shale. Organic Geochemistry 15, 351-359.

Mahato S. B., Nandy A. K., Roy G., 1992. Triterpenoids. Phytochemistry 9, 2199-2249.

Mahato S.B., Sarkar S.K., Poddar S.G., 1988. Triterpenoid saponins. Phytochemistry 27, 3037-3067.

Mahato S.B., Sen S., 1997. Advances in triterpenoid research 1990-1994. Phytochemistry $44,1185-1236$.

Miles, D.H., Tunsuwan, K., Chittawong, V., Hedin, P.A., Kokpol, U., 1994. Boll weevil antifeedants from Eleocharis dulcis Trin. Journal of Agricultural and Food Chemistry 42, $1561-1562$.

Pant P., Rastogi R.P., 1979. The triterpenoids. Phytochemistry 18, 1095-1108.

Philp, R.P., 1985. Fossil fuel biomarkers. Applications and Spectra, Elsevier, Amsterdam. Prartono, T., Wolff, G.A, 1998. Organic geochemistry of lacustrine sediments: a record of the changing trophic status of Rostherne Mere, U.K. Organic Geochemistry 28, 729-747. 
Rullkötter, J., Peakman, T.M., ten Haven, H.L, 1994. Early diagenesis of terrigenous triterpenoids and its implications for petroleum geochemistry. Organic Geochemistry 21, 215-233.

Shiojima, K., Arai, Y., Masuda, K., Takase, Y., Ageta, T., Ageta, H., 1992. Mass spectra of pentacyclic triterpenoids. Chemical Pharmacology Bulletin 40, 1683-1690.

Spyckerelle, C., 1975. Constituants aromatiques de sédiments. PhD thesis, Université Louis Pasteur, Strasbourg, France, 134 p.

Stout, S., 1992. Aliphatic and aromatic triterpenoid hydrocarbons in a Tertiary angiospermous lignite. Organic Geochemistry 18, 51-66.

Trendel, J., 1985. Dégradation des triterpènes dans les sédiments. Aspects photochimiques et microbiologiques. $\mathrm{PhD}$ thesis, Université Louis Pasteur, Strasbourg, France, 126 p.

Trendel, J. M., Lohmann, F., Kintzinger, J. P., Albrecht, P., Chiaroni, A., Riche, C., Cesario, M., Guilhem, J., Pascard, C., 1989. Identification of des-A-triterpenoid hydrocarbons occurring in surface sediments. Tetrahedron 45, 4457-4470.

Wakeham, S.G., Schaffner, C., Giger, W., 1980. Polycyclic aromatic hydrocarbons in recent lake sediments - II. Compounds derived from biogenic precursors during early diagenesis. Geochimica et Cosmochimica Acta 44, 415-429.

Wolff, G.A., Trendel, J.M., Albrecht, P., 1989. Novel monoaromatic triterpenoid hydrocarbons occurring in sediments. Tetrahedron 45, 6721-6728.

Woolhouse A.D., Oung J.-N., Philp, R.P., Weston, R.J., 1992. Triterpanes and ring-A triterpanes as biomarkers characteristic of Tertiary oils derived from predominantly higher plant sources. Organic Geochemistry 18, 23-31. 


\section{Table captions}

Table 1: List of compounds discussed in the text with retention times, mass spectral data, tentative identification and references. 


\section{Figure captions}

Figure 1: a- Map of study area with location of the coring site. b- Location of samples selected for this study on core MA-98-3.

Figure 2: Distribution of des-A-triterpenes in the partial selected ion chromatogram $(\mathrm{m} / \mathrm{z}$ $163+177+189+203+218)$ of the aliphatic hydrocarbon fraction extracted from sample 229 . The mass spectral data, retention times and proposed identity of compounds 1 to 7 are given in Table 1.

Figure 3: Distribution of aromatic triterpenes depicted on the Total Ion Chromatogram, $\mathrm{m} / \mathrm{z}$ 145, $\mathrm{m} / \mathrm{z} 195$ and $\mathrm{m} / \mathrm{z}$ 340+342 mass chromatograms of samples 073 (a) and 229 (b). The mass spectral data, retention times and proposed identity of compounds 8 to 27 are given in Table 1.

Figure 4: Fragmentation mechanism for 24,25-dinor-arbora-1,3,5,7,9-pentaene (adapted from Hauke, 1994) and proposed fragmentation mechanism for ring A-B diaromatic derivatives of tetracyclic triterpenes with euphane or lanostane structure. Note that the structures shown are tentative.

Figure 5: Evolution of the distribution of des-A-triterpenes illustrated on the $\mathrm{m} / \mathrm{z}$ $163+177+189+203+218$ mass chromatograms in selected samples from core MA-98-3.

Figure 6: Evolution of the abundance of des-A-triterpenes and aromatic derivatives of triterpenes as compared to Rock-Eval parameters along core MA-98-3. a- Total Organic 
Carbon (TOC; \%), b- Hydrogen Index (HI; mgHC. ${ }^{-1}$ TOC), c- Mineral Inorganic Carbon (MINC; \%), d- True temperature of maximum release of hydrocarbonaceous compounds during pyrolysis $\left(\mathrm{TpS} 2 ;{ }^{\circ} \mathrm{C}\right)$, e- Evolution of the $\delta \mathrm{D}$ values of the triacontanic acid through the core (Jacob, 2004), f- Relative abundance of des-A-triterpenes (arbitrary unit), gRelative abundance of des-A-lupane as compared to other des-A-triterpenes (arbitrary unit), h- Relative abundance of aromatic derivatives of triterpenes (arbitrary unit).

Figure 7: a- Picture of the lake margins illustrating the development of a belt of Eleocharis $s p$. (spike-rush) around the lake, between 1 and $3 \mathrm{~m}$ depth; b- Schematic scenario of the paleoenvironmental changes that occurred around Lake Caçó during the last 20,000 yrs explaining the evolution of triterpene derivative fingerprint in the sediments. 
Table 1

\begin{tabular}{|c|c|c|c|c|c|}
\hline $\begin{array}{c}\text { Peak } \\
\mathrm{N}^{\circ}\end{array}$ & Ret. time $\mathrm{N}$ & $\begin{array}{l}\text { Molecular } \\
\text { mass }\end{array}$ & $\begin{array}{c}\text { Most significant ions } \\
\text { (by decreasing relative abundance order) }\end{array}$ & Tentative identification & References \\
\hline \multicolumn{6}{|c|}{ Des-A-triterpenes } \\
\hline 1 & 37.83 & 328 & 189,204,313,161,328,161,218 & $\mathrm{C}_{24} \mathrm{H}_{40}$ des-A-olean-13(18)-ene & A, B \\
\hline 2 & 37.99 & 328 & 203,218,189,231,313,161,175,328,243 & $\mathrm{C}_{24} \mathrm{H}_{40}$ des-A-olean-12-ene & A, B \\
\hline 3 & 38.28 & 328 & 313,189,161,175,204,328,218 & $\mathrm{C}_{24} \mathrm{H}_{40}$ des-A-urs-13(18)-ene & A, B \\
\hline 4 & 39.07 & 328 & $218,313,189,231,203,243,328$ & $\mathrm{C}_{24} \mathrm{H}_{40}$ des-A-urs-12-ene & A, B \\
\hline 5 & 39.83 & 330 & $163,149,191,177,206,287,217,315,330$ & $\mathrm{C}_{24} \mathrm{H}_{42}$ des-A-lupane & B, C (235), D, E \\
\hline 6 & 41.92 & 328 & $161,313,175,149,191,328,231,257,243$ & $\mathrm{C}_{24} \mathrm{H}_{40}$ des-A-arbor-9(11)-ene & $\mathrm{F}$ \\
\hline 7 & $\begin{array}{l}42.07 \\
\text { Aromatics }\end{array}$ & 330 & $191,177,206,315,330,219,233$ & $\mathrm{C}_{24} \mathrm{H}_{42}$ des-A-oleanane/ursane & $\mathrm{E}$ \\
\hline 8 & 50.82 & 336 & $145,157,172,336,285,217$ & $\mathrm{C}_{25} \mathrm{H}_{36}$ pentanor-lupa-1,3,5(10)-triene & \\
\hline 9 & 52.02 & 380 & $145,351,173,380,213$ & $\mathrm{C}_{28} \mathrm{H}_{44}$ Unknown & \\
\hline 10 & 53.13 & 380 & $172,145,157,380$ & $\mathrm{C}_{28} \mathrm{H}_{44} \quad$ Unknown & \\
\hline 11 & 54.16 & 376 & $145,172,156,189,204,361,376$ & $\mathrm{C}_{28} \mathrm{H}_{40}$ dinor-oleana(ursa)-1,3,5(10),12-tetraene & G (27, 28 or 31), H (38,34,35,31), I (7c), J (18) \\
\hline 12 & 54.43 & 376 & $170,155,145,209,285,225,361,376$ & $\mathrm{C}_{28} \mathrm{H}_{40}$ dinor-oleana(ursa)-1,3,5(10),13(18)-tetraene & G (29) \\
\hline 13 & 55.3 & 376 & $158,145,143,204,361,376$ & $\mathrm{C}_{28} \mathrm{H}_{40}$ dinor-oleana(ursa)-1,3,5(10),12-tetraene & G (31), H(38,34,35,31), I (7b), J(20) \\
\hline 14 & 55.44 & 376 & $195,207,361,376,249,181,221,235$ & $\mathrm{C}_{28} \mathrm{H}_{40}$ lanosta(eupha)pentaene & \\
\hline 15 & 55.55 & 378 & $145,157,172,378$ & $\mathrm{C}_{28} \mathrm{H}_{42}$ dinor-oleana(ursa)-1,3,5(10)-triene & G (32), H(43), N (F) \\
\hline 16 & 55.84 & 340 & $255,188,325,340$ & $\mathrm{C}_{26} \mathrm{H}_{28}$ tetranor-oleana(ursa)-1,3,5(10),6,8,11,13-octaene & G (46) \\
\hline 17 & 56.05 & 360 & 207,181,345,360,221,195 & $\mathrm{C}_{27} \mathrm{H}_{36}$ nor-lanosta(eupha)hexaene & \\
\hline 18 & 56.3 & 376 & $195,361,207,181,376,249,235,221$ & $\mathrm{C}_{28} \mathrm{H}_{40}$ lanosta(eupha)pentaene & \\
\hline 19 & 56.42 & 340 & $255,340,270,239,325,283$ & $\mathrm{C}_{26} \mathrm{H}_{30}$ tetranor-oleana(ursa)-1,3,5(10),6,8,11,13-octaene & G (46), K (D') \\
\hline 20 & 57.56 & 342 & $342,218,231,243,257,327,271,285$ & $\mathrm{C}_{26} \mathrm{H}_{30}$ tetranor-oleana(ursa)-1,3,5(10),6,8,11,13-heptaene & G (39), H (39), J (22), K(F',H'), L(XI, XII), M(19) \\
\hline 21 & 57.77 & 374 & $195,207,374,359,221$ & $\mathrm{C}_{28} \mathrm{H}_{38}$ lanosta(eupha)hexaene & \\
\hline 22 & 57.84 & 378 & $145,157,172$ & $\mathrm{C}_{28} \mathrm{H}_{42}$ dinor-lupa-1,3,5(10)-triene & $\mathrm{I}(7 \mathrm{a}), \mathrm{J}(21), \mathrm{N}(\mathrm{F})$ \\
\hline 23 & 57.88 & 342 & $257,342,242,228$ & $\mathrm{C}_{26} \mathrm{H}_{30}$ tetranor-oleana(ursa)-1,3,5(10),6,8,11,13-heptaene & G (42), H(40), M(20), J(23) \\
\hline 24 & 58.12 & 342 & $257,342,243,299$ & $\mathrm{C}_{26} \mathrm{H}_{30}$ tetranor-lupa-1,3,5(10),6,8,11,13-heptaene & G (43), H (47), L(XII), M(21) \\
\hline 25 & 58.54 & 374 & $195,207,374,221$ & $\mathrm{C}_{28} \mathrm{H}_{38}$ lanosta(eupha)hexaene & $\mathrm{H}(42)$ \\
\hline 26 & 58.63 & 374 & $145,157,172,325$ & $\mathrm{C}_{28} \mathrm{H}_{38}$ dinor-oleana(ursa)-1,3,5(10),12,14-pentaene & G (38) \\
\hline 27 & 58.69 & 374 & $195,374,207,221,359,281$ & $\mathrm{C}_{28} \mathrm{H}_{38}$ lanosta(eupha)hexaene & $\mathrm{G}(41), \mathrm{H}(42)$ \\
\hline
\end{tabular}

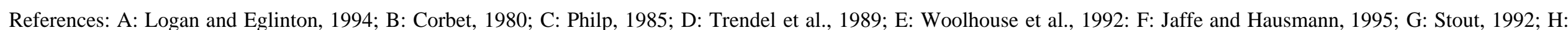

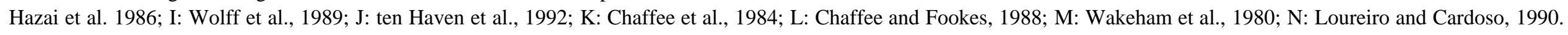
The designation of related compounds found in the reference are indicated between brackets. 
Figure 1

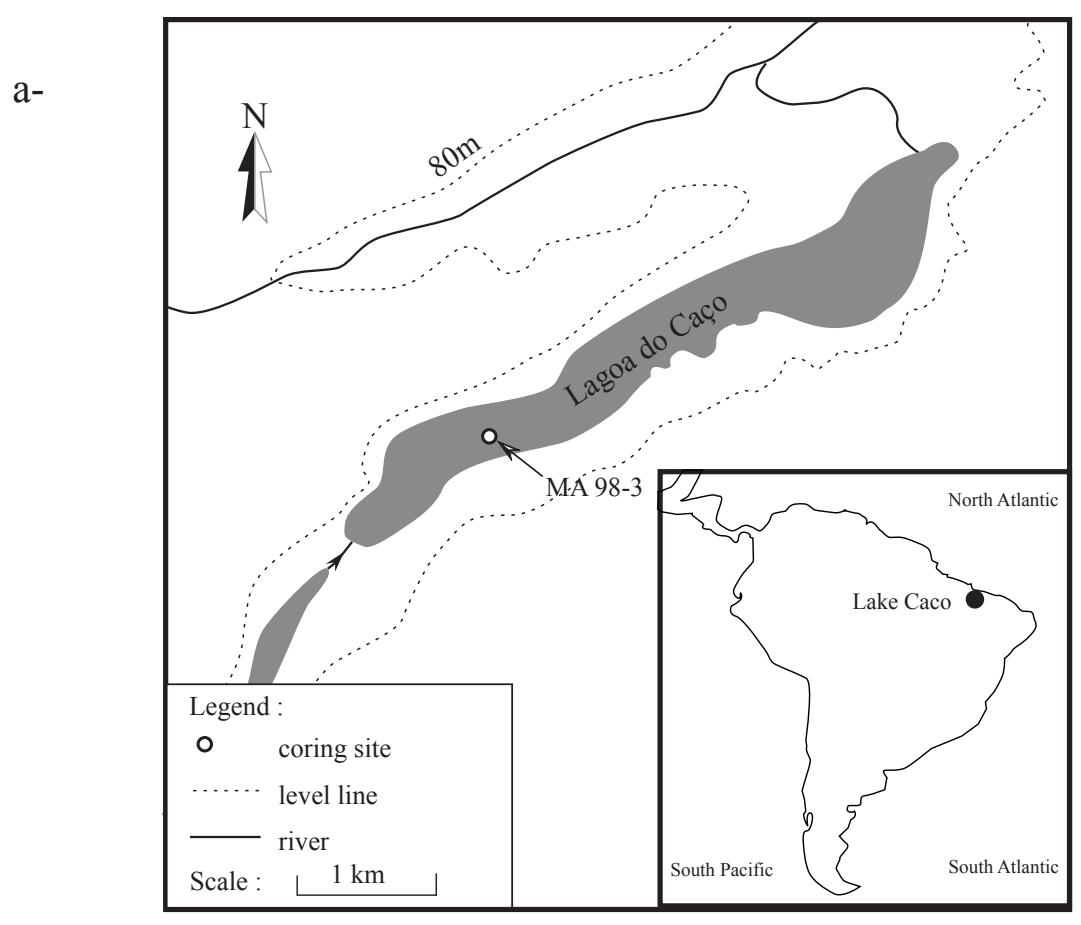

b-

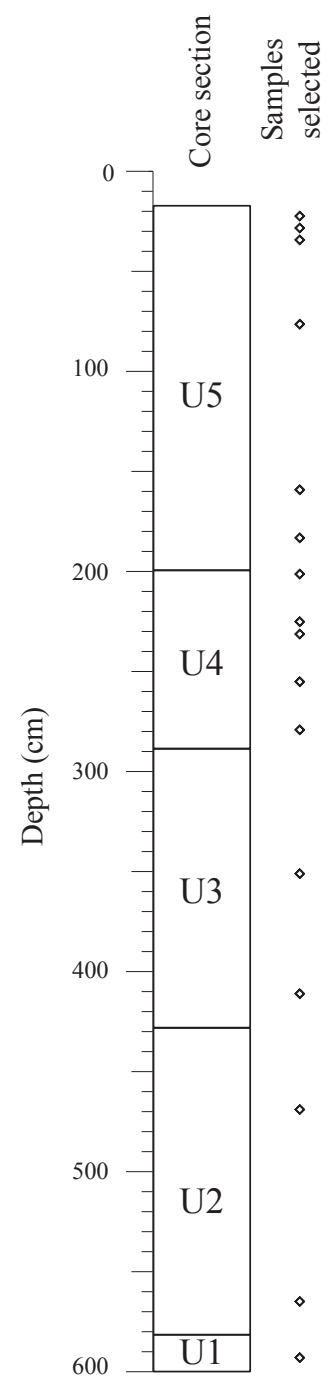


Figure 2

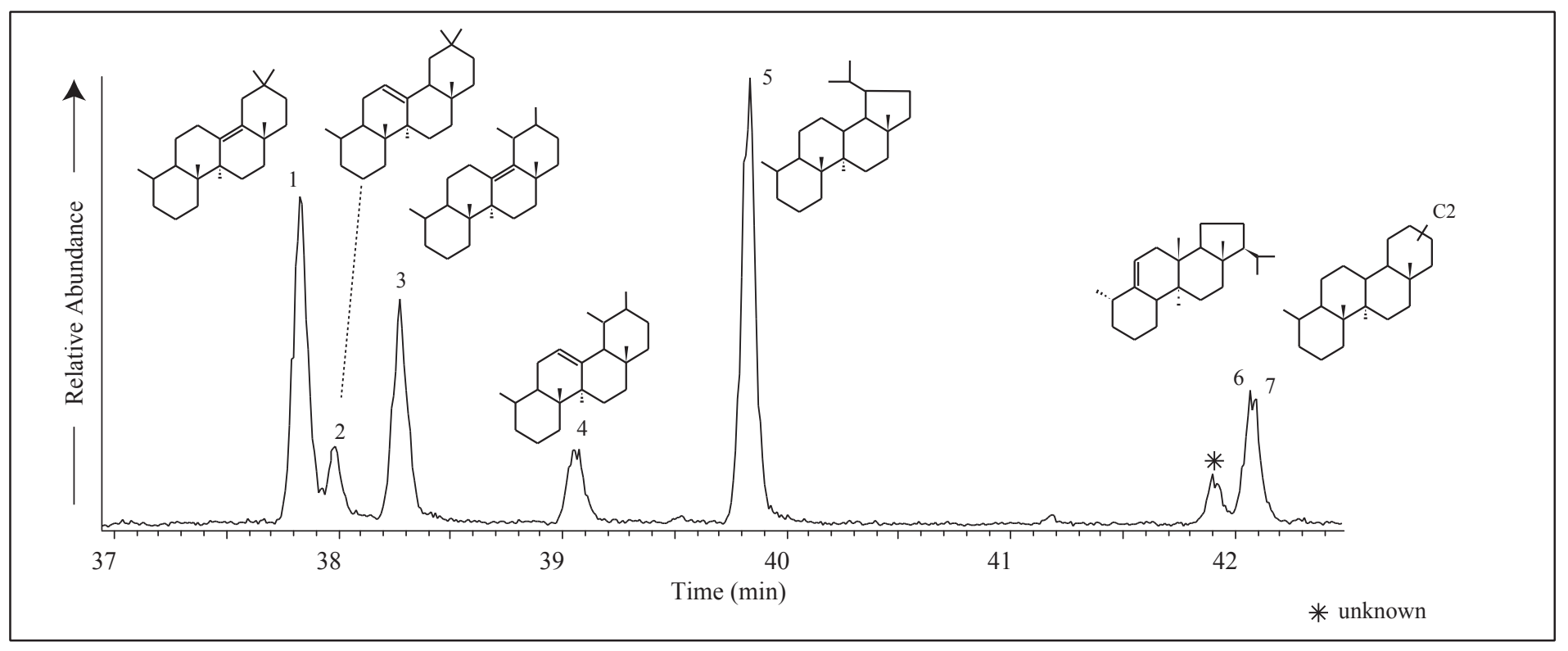




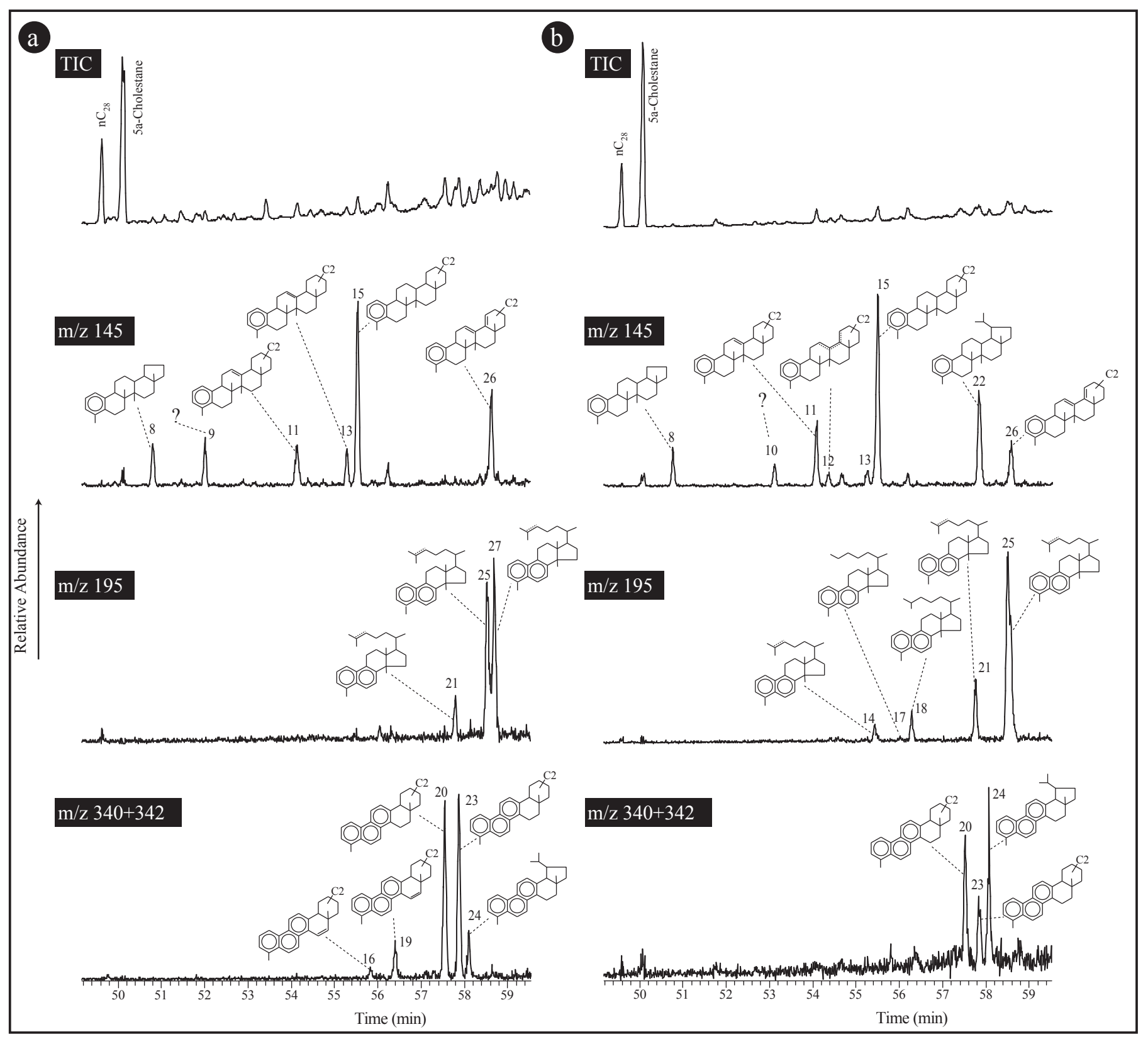

Figure 3 

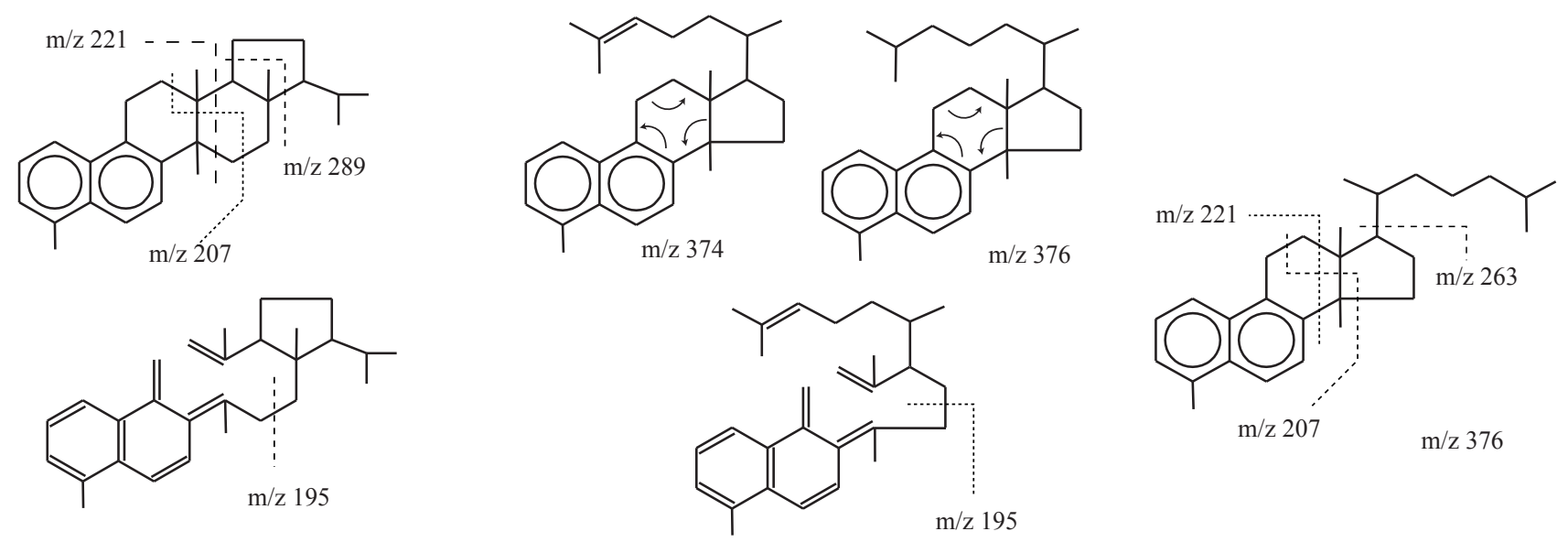

Figure 4 


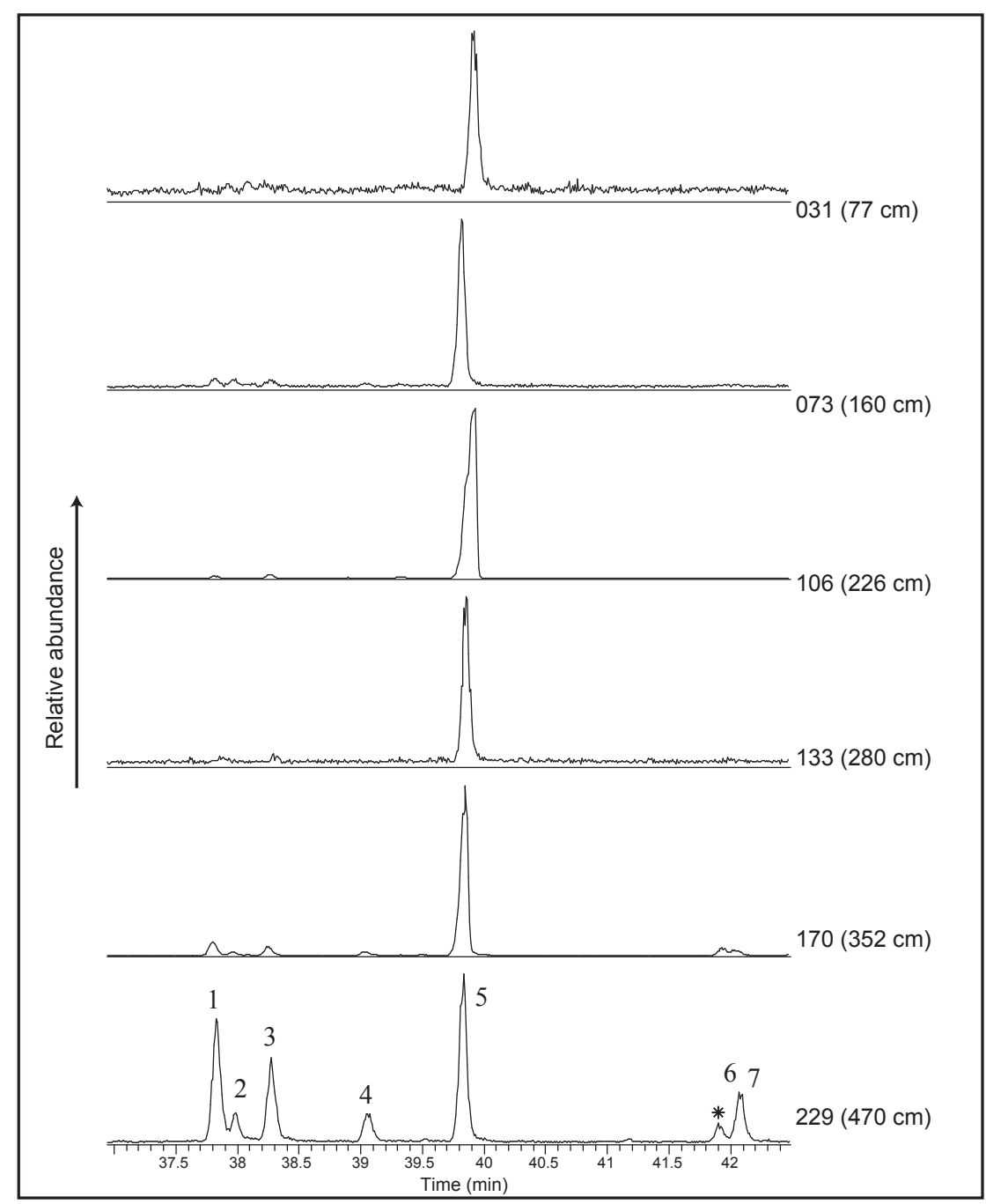

Figure 5 
Figure 6

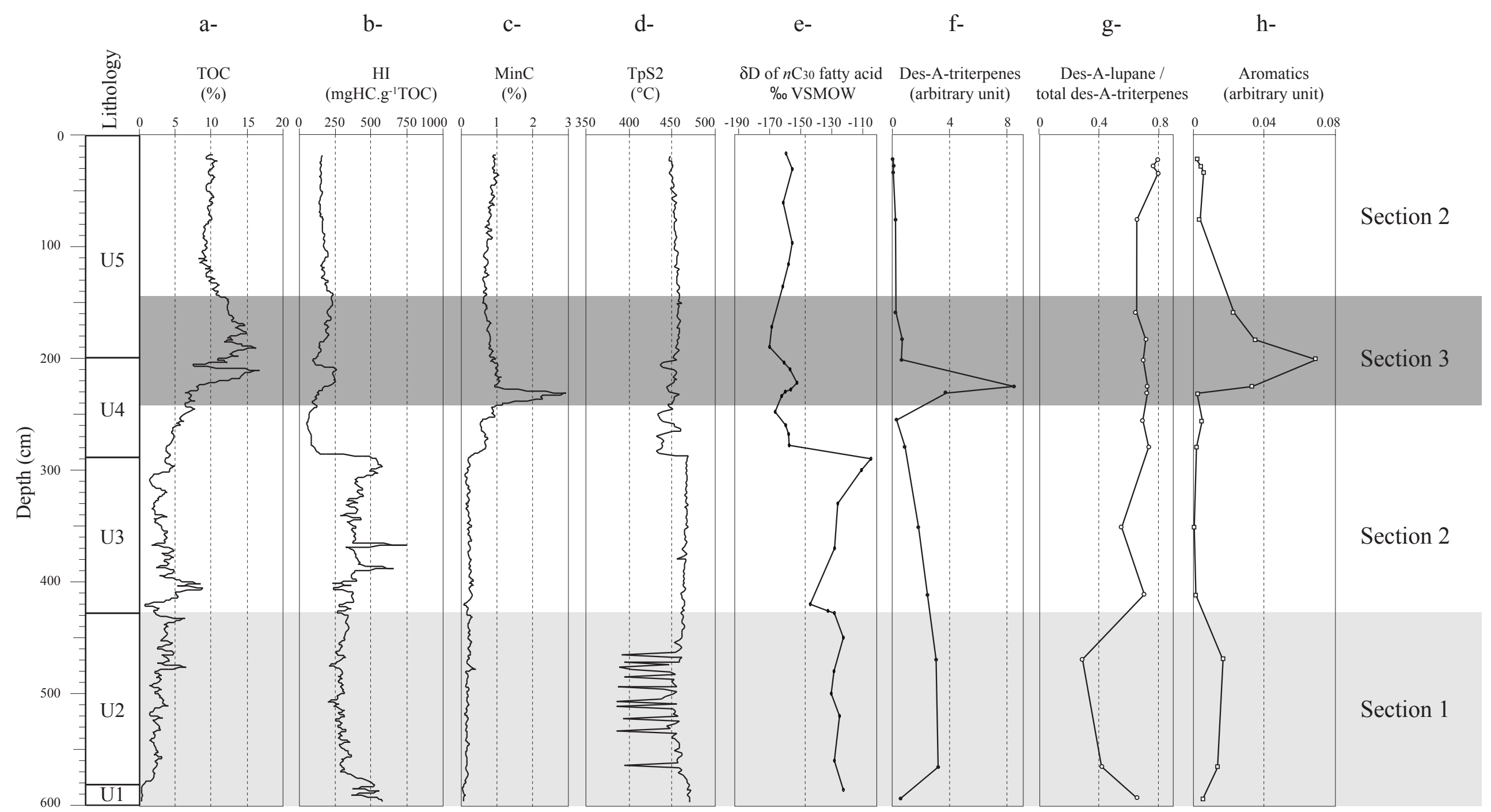


Figure 7

a-

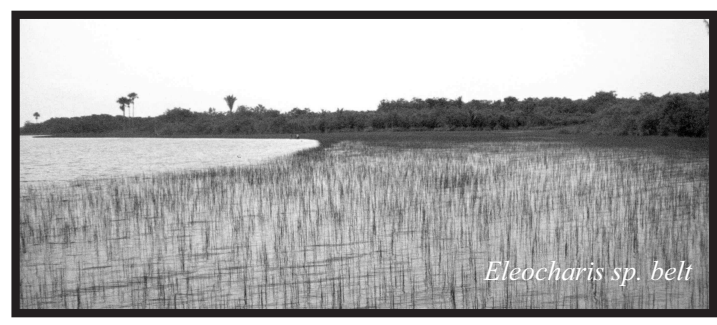

b-
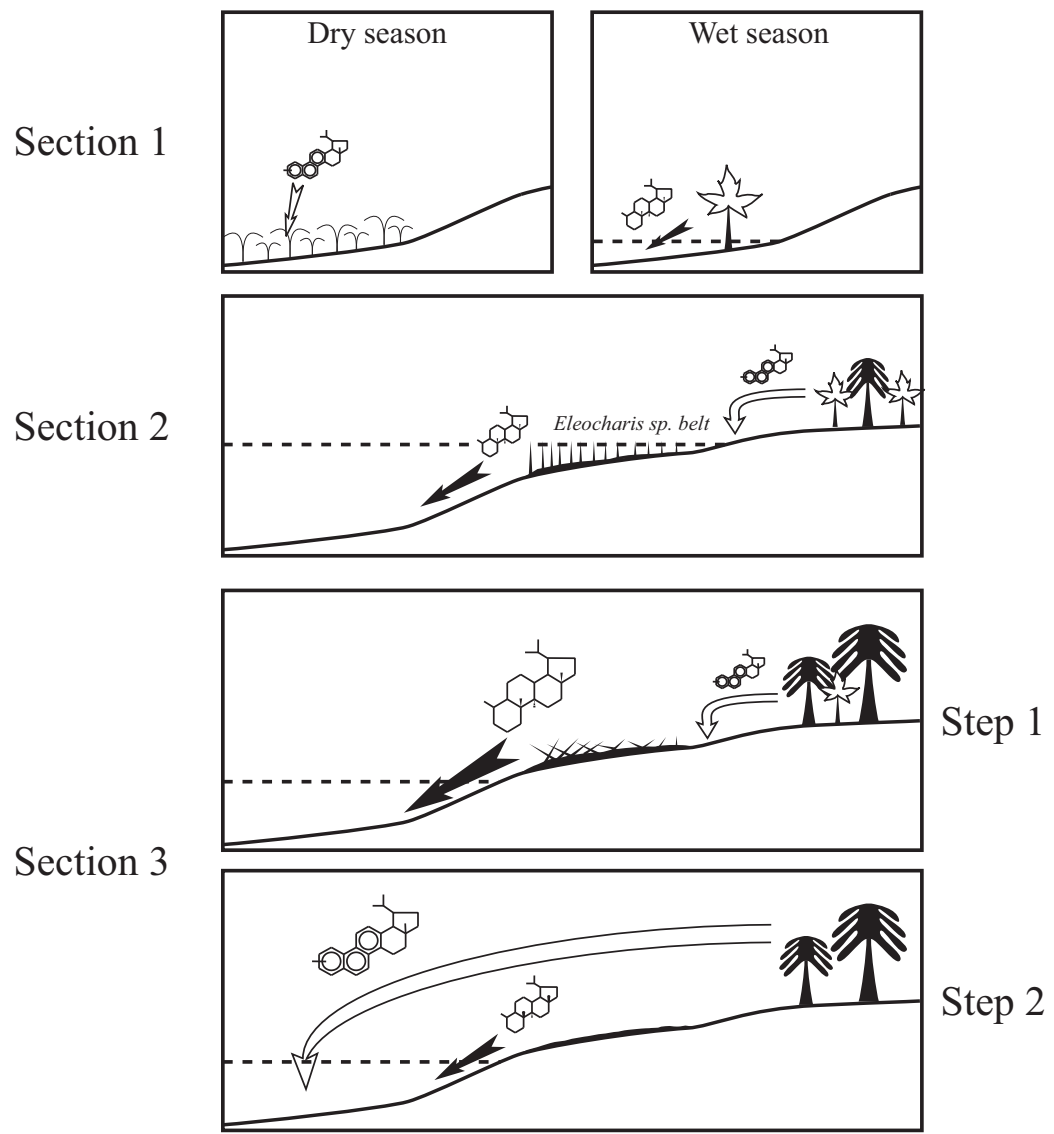

Legend :

Influx of des-A-triterpenes

Influx of aromatic derivatives of triterpenes

- - - - - Lake level 


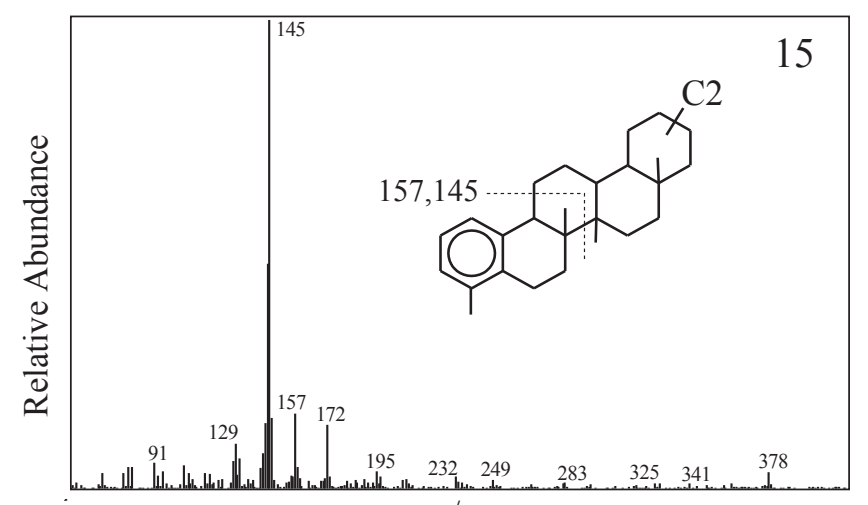

$\mathrm{m} / \mathrm{z}$
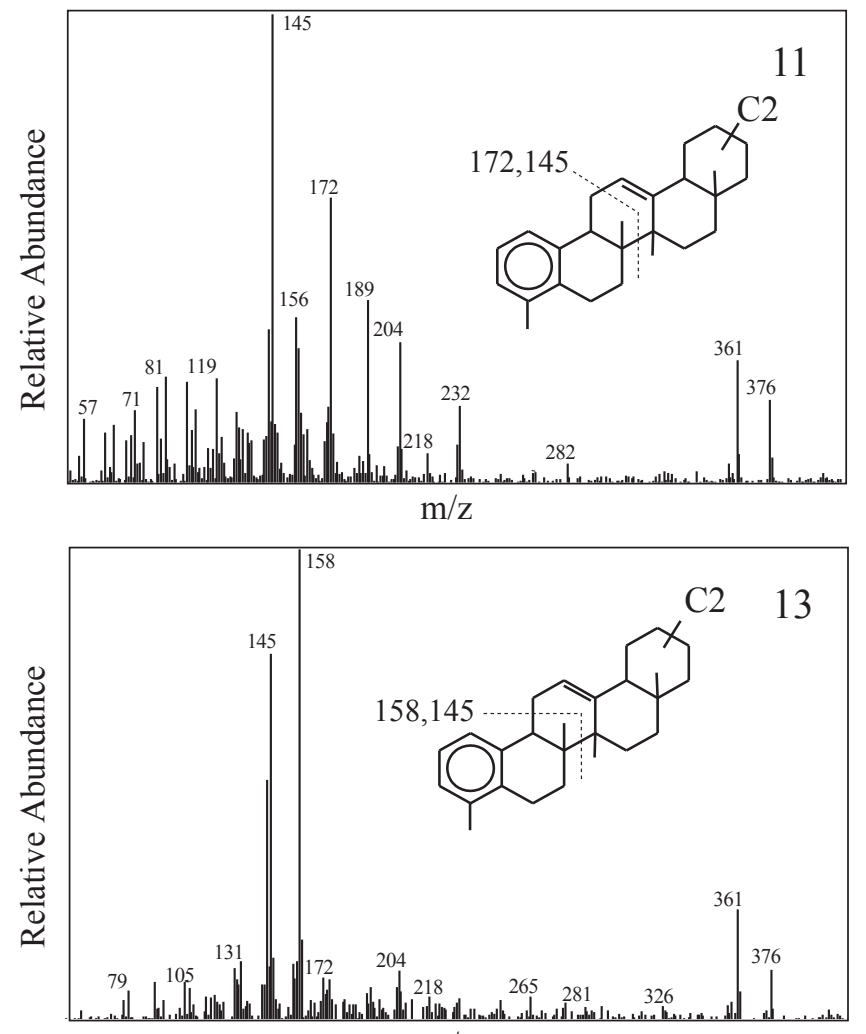
$\mathrm{m} / \mathrm{z}$

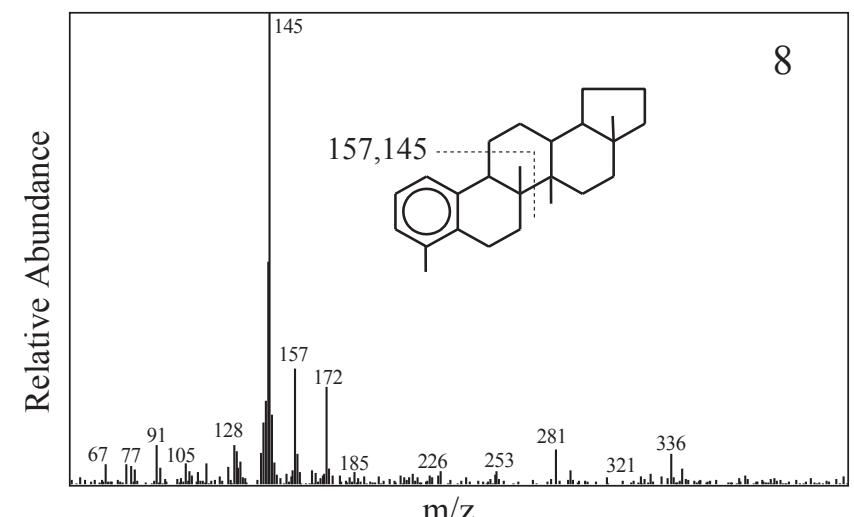

$\mathrm{m} / \mathrm{z}$

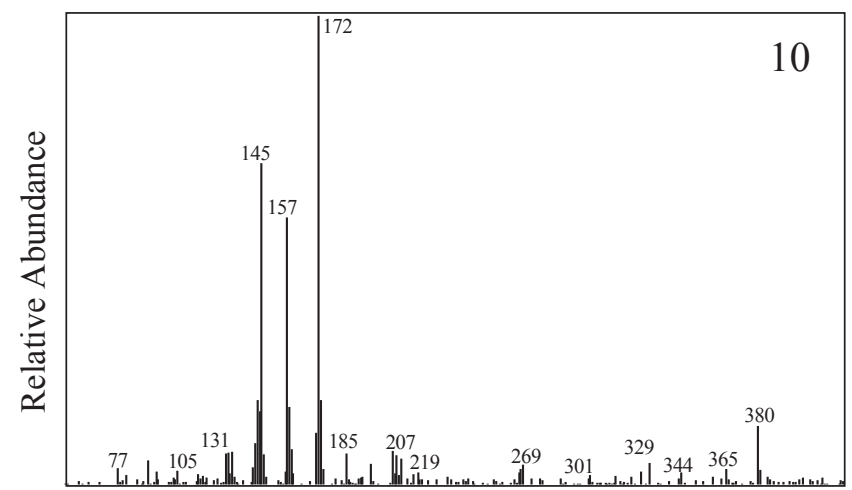

$\mathrm{m} / \mathrm{z}$

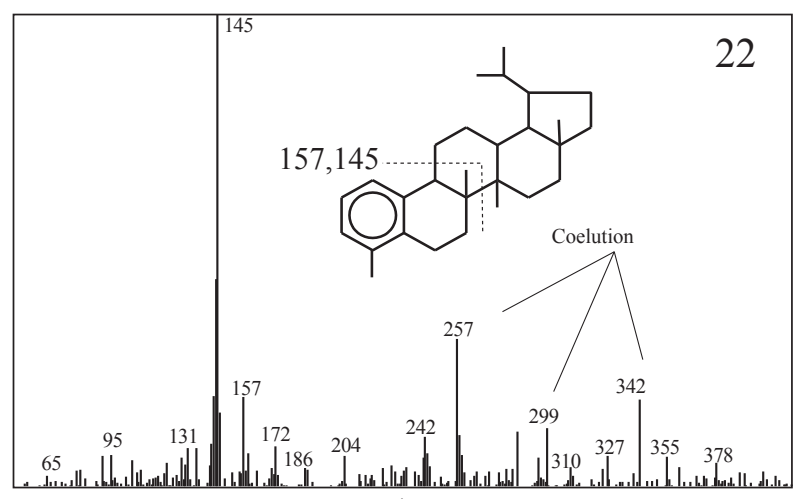
$\mathrm{m} / \mathrm{z}$
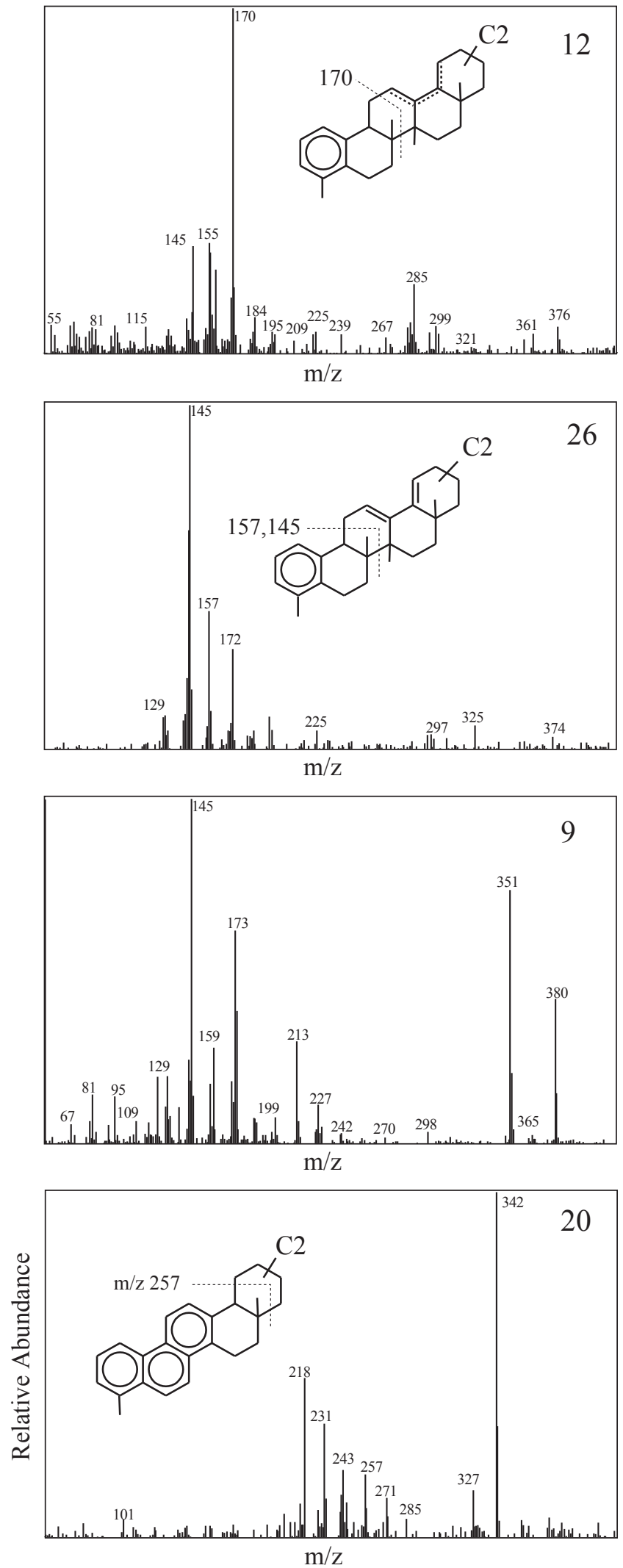

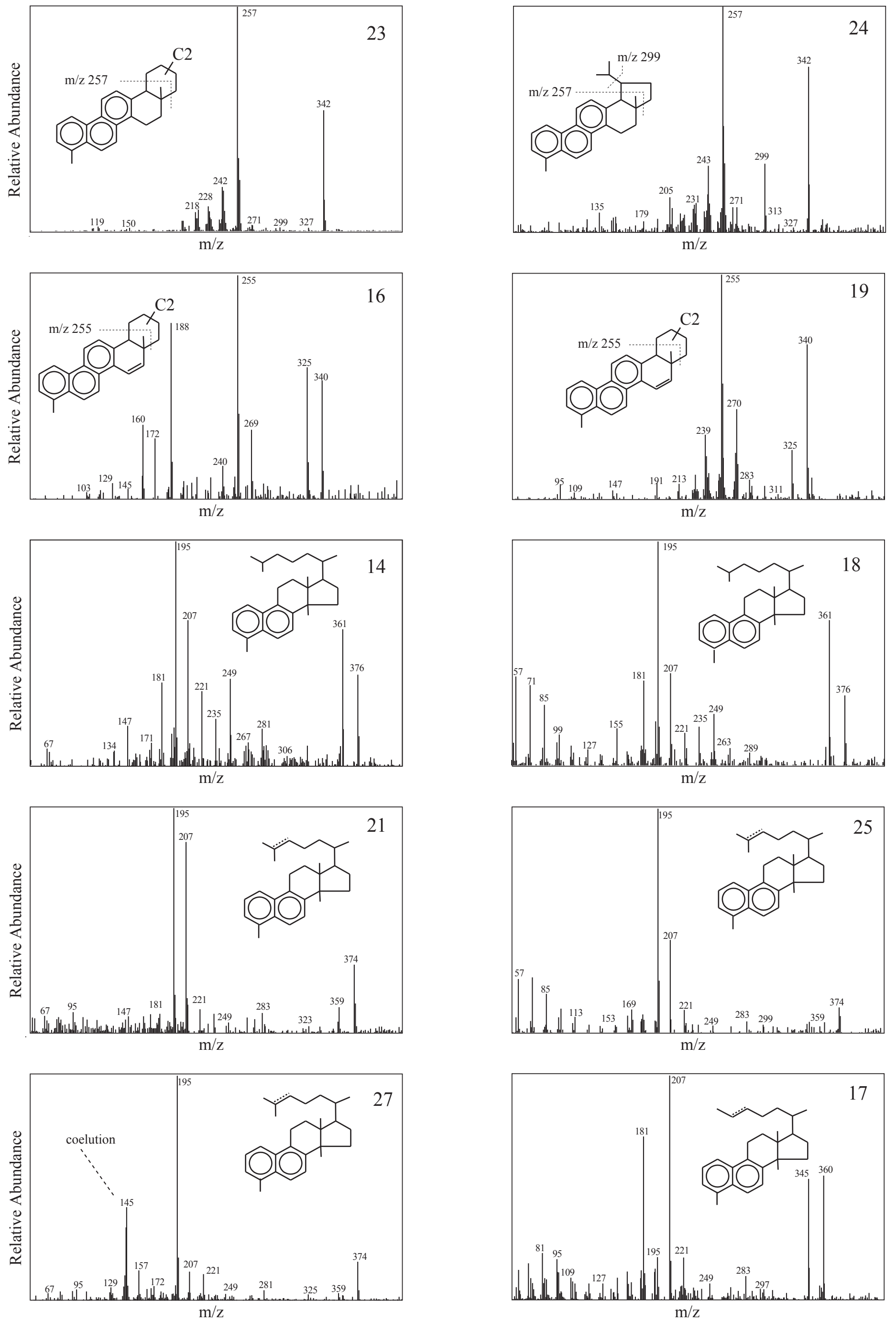